\title{
DISCLAIMER
}

This report was prepared as an account of work sponsored by an agency of the United States rovernment. Neither the I Inited States Government nor any agency themem, nor any of theit cmployecs, makes any warranty, enpress or implied, or assumes any legal liabilay or zcsponsibility lor the accuracy, compleleness, or usefulness of any informalion, apparatus, product, or proces disclused, or represents that uts use would not infringe privately owned rights. Reference herein to any specific commercial product, process, or service by irade name, trademark, manufueturer, or otherwise does not necessarily constitute or imply its endorsement, recommendation. of favoring by the Uniled States Government or any agency theteol. The views and opinions of authors expressed hetein do not necessarily state or seflect those of the United States Government or any agency therenf.

\section{MATERIALS SURFACE MODIFICATION \\ BY PLASMA BOMBARDMENT UNDER SIMULTANEOUS EROSION AND REDEPOSITION CONDITIONS}

Y.Hirooka, D.M.Goebel, R.W.Conn, G.A.Campbell, W.K.Leung

K.L.Wilson*,W.Bauer*, R.A.Causey*, D.H.Morse* and J.Bohdansky**

UCLA-PPG-992

July 1986

Deparment of Mechanical, Aerospace, and Nuclear Engineering,

Center for Plasma Physics and Fusion Engineering,

University of Califomia, Los Angeles

Los Angeles, California 90024, USA

*Physics Research Division, Sandia National Laboratories

Livermore, Califomia 94550, USA

**Max-Planck-Intinut fur Plasmaphysik,

EURATOM-Association,

D-8046 Garching, FRG

Invited paper at Workshop on Surface Modification by Mlasma-Wail Interaction at Princeton, May 1-2, 1986 (to be published in Nucl. Instr.\& Methods-B)

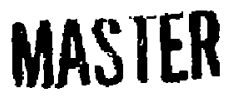

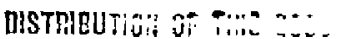




\section{IFSCAT:R}

This repont wa prepared a an accomt of hoik sponpored by

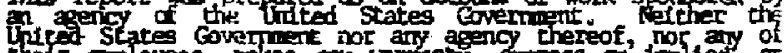

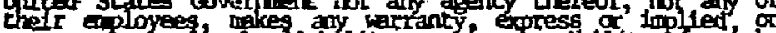

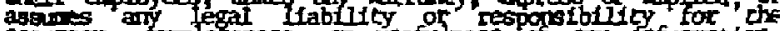
acouracy, ondileteness, $\pi$ usefulness a any information, pparators product or mocess disclosed, or pepresents that

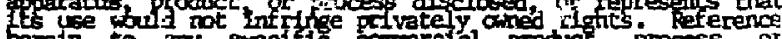

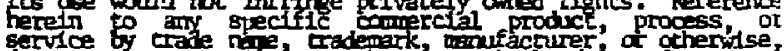

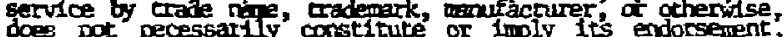
does not necessary constitute or inply its endorsement, recomendation, of ravoring or any zoncy thereof. equ tinted Stares coverninit or anty agency thereof. 
Ms. Evelyn Bolton

I..S. Department of Energy

Technical Information Center

P.O. Box 62

Oak Rtdge, IN 37831

Dear Evelyn:

Enclosed are 134 coples of IUCLA-PPG-992, "Materials Surface Modiflcation by Plasma Bombardment under Simultaneous Erosion and Redeposition Condtions." These are for distrtbution to the UC20c (subdivision only) Iist and to 78 fnternational addresses, for which I have provided plain mailing lahels.

iany thanks for your assistance in their distrtbutton.

Sincerely,

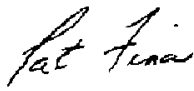

Pet Fina

enclosures in one box 
See instructions on Reverse Side

1. DOE Report No.

UCIA-PPC-99?

2. DOE Contract No.

DE-FTO3-84 EP 52104

3. Distribution Cisegory No.

UC20C (subdivision only)

4. Thaterials surface Modification by Plasma Bombardment under simultaneous

5. Type of Document (" $"$ "one) Frosion and Pedeposition Conditions

W. Scientific and technical report

b. Conference paper: Title of conference

Exact location of conference

Sponsoring prganization Date of conference

בc. Other (Specily)

6. Copies Transmitted (" $x$ " one or more)

x. Copies being transmitted lor unclassifiec standard distribution by OSTI/TIC.

Ub. Copies being trarsmitted for classified documents as contained in $\mathbf{M . 3 6 7 9 .}$

x. Copies being transmitted for special distribution.

تd. Two completely legible, reproducible copies being transmitted to OSTITIC.

De. Thisty copies being transmitted to DSTI/TIC for OSTI processing and NTIS sales.

7. Recommended Distribution (" $x$ " one)

$x_{\text {g. }}$ Unrestricted, unlimited distribution.

Make available only ib. Classified- 10 M-3679 addressees only.

$\therefore$. To U.S. Government agencies and their contractors.

:d. To COE offices only.

e. To DOE and WPAS contractors.

:I. To DOE and any DOE contractor.

$\because$ g. Within USA only.

3h. Other-specify in item 14 below.

Ji. Rafer all requesss to

8. Recommended Announcement (" $x$ " one)

3. Unrestricted, unlimited announcernent.

-b. Limit to U.S. Govt. agencies and contractors.

Ic. Limit to QOE anf WPAS contractors.

e. Limit to section 148 contractors.

I. Limit to authorized classifiec sites orly.

चd. Limit to applied technology contactors.

9. Furure Handling of Limited Reparts

Alter |Datel

this report may be reprocessed as item 7 .

and $B$.

19. Reason for Resiriction Recommended in 7 or B abnye. (Explain fully)

11. Patent and Technology Transfer Information

Does this information product disclose any new equipment, process, or material? $\mathbf{X}^{\mathrm{Na}} \quad \square$ Yes If so, identify page nos.

Has an invention disclosure been submitted to DDE covering any aspect of this information product? $\mathrm{X}$ No $\square$ Yes

If yes, identify the DDE disclosure number and to wham the disclosure was submitted.

Are there any patemtrelated objections to the release of this information product? $\mathrm{X}$ No $\square$ Yes If so, state these objections.

("x" onel Fo. DOE patent clearance has beer yranted by responsible DOE patent group.

[] b. Document has been sent to responsible OOE patent group fof ciearance.

12. Does this information product contain? (Check all applicable boxes)
$\square$ Coprrighted material (attach release)
$\square$ Restricted data
C Proprietary information tpage numbers
Z Formerly restricted data
C National security information
[] Applied technology

$\checkmark$ Section 148

* Other (explain) applied plasma ohysics

13. Copy Aeproduction and Distribution

Total number of copies reproduced Number of copies distributed outside originator (exclude copies to OSTI/T/C)

14. Additional information or Pe 1,1 arks (Contimue on separate sheet, it necessary)

15. Submitted by (Name and Position) (Please print or typel

Drganization

Pat Fina Signature
Date $8 / 5 / 86$ 


\section{INSTRUCTIONS}

Who uses this torm: All DOE officas and DOE contraciors except thase conteactors aud grantecs specifically instructed by their DOE contract administratar to use the shorter Form DOE $F$ 1332.10.

Whan to use: Submit one copy of this lorm with cach report sitle that is sent to the DOE Office of Scientific and Technical Informa tion (OSTI) in accordance with the requirements of DOE Orde: 1430.1. Add tional injtructions concerning report preparation. etc. can be found in DOE Order 1430.2 . Questions may be refered to OSTI on FTS 626-1268 or commescial 615.576-126e.

Whore to send: Forward this $t_{i}$ m

U S. Derodriment of Energy

Offict of Scennitic and Technicah Intormation

Technical ! hformation Center

P. O. $30 \times 62$

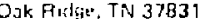

liem instructions:

Iterr 1. A stanciard reuart code svstem has been escablished lor number/"y DOE reports. A uniqun number that is complete and accuralt is essential. The following specilic instructions apply

idi DOE Program Office Reports-- Use DOE/and the two lettris Idencifying the Assistant Secretary under whose authority the program of fice operates at the busirning of the report number. Comolete the number whth doshes and the report sequence number as obtained from the Chief of Printing Procurement (MA-234,2T), Example: DOE/NE-193.

tb) DDE Field Organization Reports - Use DOE land the two tetters identifying the organization responsibla fo: $:$ in report (e.g., Of for Oak Ridge: BP for Bonncuille Pawer, etc.). Comple te the number $w$ th dashes and a report sequence number as assigned by the Technical Information Olficer at the site. Example: DOEJOR-759.

(c) Major Project Otice Reports-Use DOE/and the two or tl:-re digit identifier for the organization respansible for the report le.g.. LLW for Low Leval Waste, etc.l. The identifiers will be assigned by OSTI. Complate the number with dashes and a report sequence sio iber as assigned at the project iffice, Exampte: DOE $/$ LLW-198.

(d) Contractor Raports-Maior contractors have betri assigned report codes by DST1, Other contractors will use DOE/and the final swen characters (two tetters pind five digits) from the applicable contract or gront number. A slash wark must separate the letters from the digits. Complete the number with dashes followed by a sequential number for pach peport generated Lider the contract. Example for :he first report generated under contract number DE-ACO3-79NE01834: DUE/NEJ01834-1.

Reports that are issucd in multivolumes, parts, or revisions. et $c$., should be numbered as follows:

$$
\begin{aligned}
& \text { DDE/NE/O1834-.1 Yol, } 1 \\
& \text { DDE/NE/01834.-1 Pt. } 1 \\
& \text { DOE/NE/01834-1 Aev, } 1
\end{aligned}
$$

Caution: Feport numbers are to be structurfet exaet.y as specified in the above examples. Modifi. cations, if essential, must be approved by OSTI.

Itnm 2. I Isert DOE contract rumber under which the work was funded.

Ifem 3 . Insert the appropriate distribution category from DOE/TIC 4500 or M-3679 for unclassified and classilied documents, respectively, whethet ar nof printed for standard tistribulion.

Itom 4. Give tith thactly as on the document itself unless title is classified. In thist case, omit tinle and state "classified titie" in the space for Item 4.
Item 5. Selfexplandiory.

Item 6. a. If box a is checked, the number of copies specified for the appropriate catcyory or categories in DOEITIC-4500 whll be forwarded to OSTI for distribution.

h. If bax b is chacked, the number ol copies as specified in M-3579 for QSTI/TIC \$hould be provided. If OSTI is to make standard distribution, so indicate in item 14.

c. If box $c$ is chacked, malling labels should be provided OSTI if oossitiltr.

d. If toox of is checked a: least one capy will be original ribuor or olf set ond be completet, tapible as per DOE Order 7430.2. A ish-contrast xerox copy is acceptoble as a second reproducible copy, Classified ducumertssend alte copy pxcept wing: stistribution require; more copjos.

e. If box e is cliecked, 30 copies will be forwardtad to OSTITIC.

Itom 7. Distribution is rnade 6 , OSTI usıng slandard distribution lists or on request. Limitations and restrictions should not be placad on the distribution of DOE funded R\&O results uniess the submiting site has recejved DOE programmatic guitiance to do so.

It hax a is checked lor an unclassified doçument. it may be distribu led by OSTITTIC lafter palcri cluarancel to addressetes listed in DOE/TIC 4500 for the appropriate distribution category. The reports ave also provided to the National Technical Information Service fr: sale tu the public.

If box b is checked for classified decument, it may be distributed by OSTI to addressees listew in $M .3679$ for the appropriate distribution category unless distributed by the originaring site.

If any box other than $a$ is checked, the recommended imucations will be followed unless as TI receives other instructions from the responsible DOE program division.

Box h or i may be checked in order to specify special instructions, such as "Make available only as specifically approved by the program division."

Item B. DOE is obligated to announce (printed or electronic media) the results of its faderally funded $A B($ to the widest extent possible. Siles should not recorimend announcement limitations unless they have recaived DOE programmatic guidance to do so. Recommended announcement Jimitations can be less restrictive than recommended distribution limitations.

Itern 9. For limited reoprts, or iginators are strongly encouraged to specify unlimited or less-limited processing alter a certain time period. Indicate the date and the less limited reprocessing categories from items 7 and 8 .

Jtem 70. Selfexplanainir.

Item 11. It is assumed that there is no objection to publication from the standpoint of the originating organization's patent interest. Otherwise explain in tzem 14.

Item 12. If the proprietary information block is checked, give the page nurmbers if possible.

Inem 13. Selfexplanatory.

Irom 14, Self explanó ory.

Ifom 15. Enter name of person to whom inquiries concerning the recornmendations on this form may be a-jissed. Prease give FTS phone number if possible. 


\title{
MATERIALS SURFACE MODIFICATION BY PLASMA BOMBARDMIENT UNDER SIMULTANEOUS EROSION AND REDEPOSITION CONDITIONS
}

\author{
Y.Hirooka, D.M.Goebel, R.W.Conn, G.A.Campbell, and W.K.Leung \\ Deparment of Mechanical, Aerospace, and Nuclear Engineering, \\ Center for Plasma Physics and Fusion Engineering. \\ University of California, Los Angeles \\ Los Angeles, California 90024, ISA \\ K.L.Wilson, W.Bauer, R.A.Causey, end D.H.Morse \\ Physics Research Division, \\ Sandia National Laboratories \\ Livermore, California 94550, USA \\ J.Bohdansky \\ Max-Planck-Intitut fur Plasmaphysik, \\ EURATOM-Association, \\ D-8046 Garching, FRG
}

\begin{abstract}
/ BSTRACT
The first in-depth investigation of surface modification of materials by continuous, high-flux argon plasma bombardment under simultaneous erosion and redeposition conditions have been carried out for copper and 304 stainless steel using the PISCES facility. The plasma bombardment conditions are: incident ion flux range from $10^{17}$ to $10^{19}$ jons $\mathrm{sec}^{-1} \mathrm{~cm}^{-2}$, total ion fluence is controlled between $10^{19}$ and $10^{22}$ ions $\mathrm{cm}^{-2}$, electron temperature range from 5 to $15 \mathrm{eV}$, and plasma density range from $10^{11}$ to $10^{13}$ $\mathrm{cm}^{-3}$. The incident ion energy is $100 \mathrm{eV}$. The sample temperature is between 300 and $700 \mathrm{~K}$.

Under redeposition dominated conditions, the material erosion rate due to the plasma bombardment is significantly smaller (by a factor up to 10) than that can be expected from the classical ion beam sputtering yield data. It is found that surface
\end{abstract}


morphologies of redeposited materials strongly depend on the plasma bombardment condition. The effect of impurities on surface morphology is elucidated in detail. Firstorder modelings are implemented to interpret the reduced erosion rate and the surface evolution. Also, fusion related surface properties of redeposited materiais such as hydrogen seemission and plasma driven permeation have been characterized.

\section{INTRODUCTION}

Erosion of materials for plasma interactive surface components such as limiters and divernor plates can be a major source of impurities in operating plasmas in a magnetic fusion device. These impurity elements will be reionized within the plasma by electron

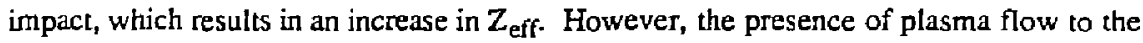
edge region leads to a redeposition of reionized impurities on surface components [1]. For long-pulse or steady-state devices, material erosion can also lead to a shortened lifetime of surface components. However, the role of redeposition is still unclear. It may reduce the net erosion rate of materials, but it will also modify the surface morphology in a yet-to-be explored manner. Furthermore, the modified surface morphology and erosion behavior of materials might be influencial one another.

In our previous work [2], the first non-tokamak, controlled piasma-wall interaction study was conducted using the PISCES facility with the main objective of understanding the mechanism of simultaneous erosion and redeposition behavior of materials. It was found that redeposition of materials resulted in a reduction of the ner erosion yield relative to the classical sputtering yield. Also, the preliminary scanning electron microscope observation indicated strongly modified surface morphologies by plasma bombardment. In the present work, extensive characterization of redeposited materials has been done to elucidate the impact of surface modification by plasma bombardment on a wide range of 
fusion engineering. This paper presents the first results of detailed investigation of surface modification of materials by plasma bombardment under simultaneous erosion and redeposition.

\section{EXPERIMENTAL PROCEDURE}

The PISCES facility and material experiments were previously described in detail elsewhere $[2,3,4]$. Here, the experimental procidure is outlined. A schematic diagram of the taget sample and movable Langmuir probe in the linearly magnetized plasma strean is shown in fig.1. A mechanically polished disk sample with a diameter of $2.5 \mathrm{~cm}$ was placed on a target holder. The magnetic field is 250 gauss and perpendicular to the target surface. The Langmuir probe was moved in front of the target surface to measure the electron temperature and plasma density. During the probe measurement, the sample surface was protected by a movable shutter plate. The electron temperature was typically in the range from 5 to $20 \mathrm{eV}$, and the plasma density was in the range from $10^{11}$ to $10^{13} \mathrm{~cm}^{-3}$.

The plasma bombardment energy was set at $100 \mathrm{eV}$ in this study. The ion flux was in the range from $5 \times 10^{17}$ to $5 \times 10^{18}$ ions $\mathrm{sec}^{-1} \mathrm{~cm}^{-2}$. This means that the target surface is subject to a heat flux up to $80 \mathrm{~W} \mathrm{~cm} \mathrm{~cm}^{-2}$. Consequently, the target temperature was controlled by ail or vater cooling, depending on the heat flux and selected temperature. The target was set at iemperatures between 300 to $1000 \mathrm{~K}$, which can be measured by a thermocouple attached on the sample holder. The total ion fluence was varied in the range from $10^{19}$ to $10^{22}$ ions $\mathrm{cm}^{-2}$. Plasma bombarded samples were weighed to evaluate the net erosion and analyzed with a variety of surface analysis techniques including SEM (Scanning Electron Microscopy), EMPA (Electron Micro Probe Analysis), AES (Auger Electron Spectrcscopy), SIMS (Seciondary Ion Mass Spectroscopy), NRA (Nuclear Reaction Analysis) and RBS (Rutherford Backscattering Spectroscopy). 


\section{GENERAL CONSIDERATIONS OF EXPERIMENTAL CONDITIONS}

Of particular interest is to compare the PISCES and conventional ion beam experiments from a surface modification viewp sint. Historically, ion beam experiments often employed ion fluxes between $10^{13}$ and $10^{15}$ ions $\sec ^{-1} \mathrm{~cm}^{-2}$ and ion energies between 5 and $20 \mathrm{keV}$ to simulate high energy ions or charge exchange neutrals escaping from the core plasma of a magnetic fusion device [5]. The ion implantation depth in this energy range is generally above a few hundred angstroms. Under these conditions, the surface modification by both blistering and sputtering was observed, depending on the selected ion-target combination [6]. In the present work utilizing the PISCES facility, the argon ion flux is typically $10^{18}$ ions $\mathrm{sec}^{-1} \mathrm{~cm}^{-2}$, and the bombardment energy is $100 \mathrm{eV}$ to simulate the edge-plasma flow. As shown in fig.2, the ion implantation depth is quite shallow at this energy. Also, the recession depth of the surface per unit time due to sputtering at these high ion fluxes far exceeds the ion implantation depth under typical plasma bombardment conditions (see table 1). This means that the retention of implanted ions must be small compared with that for high energy ion bombandment cases. These particular features of a high flux and low energy plasma bombardment will not meet the general blistering criteria [7]. Therefore, one may well expect that sputtering is the predominant process to control the surface modification of materials in the present study, as will be shown later.

Another important comparison should be made between the nature of redeposition in the PISCES facility and in large toroidal fusion devices such as tokamaks. Due to impurity transport in the toroidal and poloidal directions, it is not surprising to see redeposited materials via elemental interchange between different surface components exposed to the plasma in a tokamak after an exlensjve period of discharge experiments[8]. Redepositing particles are generally considered to bave a wide energy distribution. As a 
result, surface coating-like films or droplets can be formed by deposition of particles with energies below the threshold value to cause subsequent sputtering of a new host substrate. This is also true for the sputter deposition or vapor deposition processes, which are standard film production techniques for miçro-electronics purposes [6].

In contrast, the target is practically the only plasma interactive component in the PISこES facility. Alșo, the linearly magnetized plasma naturally flows to the target due to the pre-sheath electrostatic potential, which is approximately $-1.5 \mathrm{kT} \mathrm{e}^{/ \mathrm{e}}$. It follows that reionized materials will be redeposited back on the original surface, guided by the magnetic and pre-sheath electrostatic fields. Consequently, the target is subject to simultaneous bombardnent of the primary plasma ions and redepositing materials ions, each accelerated by the same sheath potential drop. In this case, redepositing ions will generally erode the target surface by self-sputtering. As will be shown later in detail, trapping of redepositing ions associated with the self-sputtering process plays an important role in determining !he net eiosion yield. However, these trapped ions will be removed by subsequent ion bombardment because of the short implantation depth shown in fig 2 . Therefore, ordinary coating-like films can not be expected to grow from the redepositing materials in the PISCES facility.

\section{MODELING OF EROSION AND REDEPOSITION OF MATERIAISS}

The first-order modsling of simultareous erosion and redeposition of materials (the computer program, AREX; Analysis of Redeposition EXperiment) in the PISCES facility is outlined here for consistency although detalls can be found elsewhere[2]. Major mechanisms involved in this modeling include: (1) target sputtering by the primary plasma ions being accelerated by the negative sheath potential; (2) reionization of sputtered materials by electron impact; (3) trapf 'ng of material ions on the magnetic field lines and 
transport back to the original target surface; and (4) self-sputtering of the target by the redepositing ions, accelerated by riic same sheath potential as that for the primary plasma ions.

The sputtering yield and self-sputtering yield are calculated by Yamamura's analytic formula [9]. Velocities of sputtered particles are estimated from the well-known energy distribution [5]: $\mathrm{N}(\mathrm{F})=\mathrm{E} /\left(\mathrm{E}+\mathrm{U}_{\mathrm{s}}\right)^{3}$, where $\mathrm{U}_{\mathrm{S}}$ is the surface binding energy of tho target material. The cross section of electron impact ionization is obtained from Lotz's formula [10] and then averaged over the Maxwellian elergy distribution to estimate the rate coefficient. As an example, calculated mea: iree paths for electron impact ionization processes of spulteted copper and iron are shown in fig. 3.

The probability of redeposition is defined as the fraction, of sputtered neutrals which will be ionized within the projected space of the target, a suming that the emission of sputtered particles obeys the cosine law. The probability of redeposition, $\beta$, as shown in fig. 4 , decreases rajidy $:$ as the mean fiee path for electron impact jonization increases. Since the mean free paths for second and third ionization are appreciabiy long as shown fig.3, only redeposition associated wit:- :irst ionizatiun is :onsidered in this model. Using this probability redeposition, the totai erosivil rate can be given by the following suries:

$$
H w^{\prime} / A t=\Gamma_{s}(1-\beta)\left[1+\left[Y_{s s}-(1-R)\right\}\right] \sum_{n=0}^{\infty}\left(B Y_{s s}\right)^{n}
$$

where $Y_{S}$ and $Y_{s s}$ are the sputtering yield due to the primary plasma ions and self-sputtering yield sue to the redepositing ions, respestively. The term, $R$, is the particle raflection coefficient of redepositing ions, which can be calculated using the Monte Carlo program: TRIM[11]. Retention of implanted plasma ions is considered to be negligible compared with the total erosion of the target material. Also, the sputtering yield and self-sputtering yield are assumed to be independent of the surface morphology of the target. 
Notice that when the probability of redeposition is negligibly small, the net erosion rate estimated by eq.(1) becomes erisentially the same as the sputtering erosion due to the primary plasna ions. For a certain value of the probability of redeposition, terms after the second one of the series are negative if the self-sputtering yi:ld due to redepositing ions is smaller than (1-R), which is equivalent to the trapping coefficient. It follows directly from this that the resultant net erosion rate will be smaller than the classical sputtering erosion rate. Another important implicatiols is that the 'run-away erosion' condition for the PISCES experiment is $\beta Y_{S S}>1$, which is similar to that for a large toroidal device [12].

Although only physical sputtering cases are treated in this model, the concept of redeposition is common for both chemical and physical sputtering cases. Now, consider a typical ion-target combination to cause chemical sputtering such as hydrogen ion-carbon (graphite) interaction which often induces gaseous methane production [13]. The electron impact ionization rate coefficient for methane is comparable with that for carbon in the electron temperature range of the PISCES plasma [14]. However, methare molecules are considered to be released with thermal energies determined by the surface temperature. This implies that velocities of desorbing methane molecules are much smaller than those of physically sputtered carbon atoms. Therefore, one may well expect a short ionization mean free path and hence a high probability of redeposition for chemically sputtered products such as methane. Details of the graphite-hydrogen plasma interaction experimental data taken in the PISCES facility can be found elsewhere[15].

The experimental data for normalized erosion yields determined by the weight loss method are compared with the theory in fig.5. As theoretically predicted, the normalized erosion yield data are found to be significantly smaller than unity, which corresponds to the classical sputtering yield, when the mean free path for electron impact ionization becomes shorter than about $15 \mathrm{~cm}$. There is generally agreement between the theory and data although further improvement needs to be done. The present theory tends to overestimate the net erosion yjeld, particularly in the redeposition dominated regime. Statistically, the 
samples with strongly modified surface morphologies yield the data points which fall below the theory curve. This indicates some topographical retrapping effect of sputtered particles [6], which results in a reduction of the effective sputtering yield. This will be discussed later in detail.

\section{SURFACE CHARACTERISTICS OF PLASMA BOMBARDED MLAERIALS}

It is widely recognized that surface characteristics of plasma interactive components of a magnetir ision device can affect the entire scenario of operation of fusion devices. Among these surface characteristics, surface morphologies of redeposited materials and related issues have motivated the present study. Redeposited materials were characterize by various surface analysis techniques. These techniques include SEM, AES, SMMS, RBS, EMPA and conventional X-ray diffraction malysis. Some of the results out of these measurements are presented here.

\section{5-1. SURFACE MORPHOLOGIES OF REDEPOSITED MATERIALS}

Because of the high plasma flux utilized in the present study, the surface morphology is expected to change rapidly with time. The time evolution of surface morphologies of copper and 304 stainless steel (304SS) during Ar plasma bombardment has been investigated under typical redeposition conditions cited in table 1 . The incident ion flux was set at $1.5 \times 10^{18}$ and $\mathrm{i} \times 10^{18}$ ions $\mathrm{sec}^{-1} \mathrm{~cm}^{-2}$ for copper and 304SS, respectively. During the crese of these experiments, the plasma parameters were controlled such that the mean free path for first ionization of sputtered materials is approximately 1.5 
$\mathrm{cm}$. The target temperature was set at $320 \mathrm{~K}$ to eliminate thermal effects on the evolution of the surface morphology. These thermal effects will be described later.

The surface morphologies of redeposited copper and 304SS are shown in figs. 6 and 7 , respectively. Generally, the surface appears to be deeply etched and some grains become relieved as the ion fluence increases. This illustrates the crystalline orientation effect on the sputtering yield [5]. A detail investigation of this effect is beyond the scope of the present study. Nevertheless, one important result drawn from these experiments is that the redeposited surface does not have any particular features when compared with an ordinary sputter etched surface. Our AES surface analysis showed that theie are no major impurities on these redeposited surfaces. The bombarded $3045 S$ samples indicated somewhat chromium enriched composition relative to as-polished samples. The detail will be published later.

During this series of experiments, the net erosion yield was determined by the weight loss methot. The result is shown in fig. 8. Notice that the weight loss of the target increases linearly with increasing ion fluence. (The slope of the lines is approximately 45 degrees in the logarithmic plot.) It follows that the net erosion yield is independent of ion fluence so long as the surface morphology is no: significantly modified from that of $n$ ordinary sputtered surface. The resultant net erosion yields normalized to tice corresponding classical sputtering yields are 0.3 and 0.15 for copper and 304SS, respectively. These net erosion yields are in a relatively good agreement with the theory utlizing Yamamura's formula [9] to estimate the sputtering yields (see fig. 5). This implies that the redeposited material in the PISCES facility has essentiaily the same sputtering yield as an ordinary bulk material. 


\section{5-2. EFFECT OF MPURITIES ON SURFACE MORPHOLOGY}

In a magnetic fusion device, a number of different surface materials are directly or indirectly facing the plasina. These materials are eroded by energetic particles, and can then be redeposited elsewhere as foreign impurities. In this section, the effect of foreign impurities on the surface modification under plasina bombardment is discussed in detail.

As a preliminary attempt, molybdenum from the electrode of the Langmuir probe was doped into the Ar-plasma stream. The molybdenum electrode was set at $100 \mathrm{~V}$ negative with respect to the plasma. A certain fraction of sputtered molybdonurit atoms will be reionized and redeposited on the target surface positioned downstream (see fig.1). Under a typical redeposition condition having an argon ion flux of ' 8 ions $\sec ^{-1} \mathrm{~cm}^{-2}$, the rate at which molybdenum atoms are deposited on the target surface is roughly estimated to be in the otder of $10^{13}$ atoms $\mathrm{sec}^{-1} \mathrm{~cm}^{-2}$. This is a few percent of the atomic density of a surface monolayer. The total deposition fluence of molybdenum is $10^{14}-10^{15}$ atoms $\mathrm{cm}^{-2}$.

The surface morphologies of copper and of 304SS bombarded by Ar-plasma doped with molybdenum are shown in figs. 9 and :0,respectively. Both coppar and 304SS bombarded at ambient temperatures between 300 and $320 \mathrm{~K}$ show similar surface morphologies to those shown in figs. 6 and 7, respectively. However, copper bombarded at temperatures generally above $400 \mathrm{~K}$ shows densely populated cones, some of which have compound conical structures. Also, 304SS bombarded at temperatures above $500 \mathrm{~K}$ generally shows a coral-like winding structure. Interestingly, these microscopic features can be visually identified by the color of the bombarded surface: sputter-etched surfaces retain their original metallic colors with glitters from relieved micro-grains whereas modified surfaces have much darker colors with a felt-like appearance. These results clearly indicate that the presence of molybdenum as a foreign impurity can significantly affect the surface modification processes at elevated temperatures but has little influence at ambient temperatures. A systematic investigation of the temperature effect is under way. 
Unfortunately, there is no single theory to interpret all the impurity-induced surface morphologies. It is, however, generally consiđered that a surface impurity element. which has a lower sputtering yield than the substrate, can be a nucleus to induce protruding features [6]. One recent tharry proposed by Wehner [16] indicates that the imparity acting as a seed to grow cones must have a higher melting point than the substrate Suct impurities can be either from an extemal source or from the bulk of the substrate. The seed-substrate combinations used in the present experiment: Mo-Cu and Mo-304SS meet the primary requirement for impurity-induced suiface modification with respect to both the sputtering yield and melting point arguments.

The molybdenum-seeded cone structure on copper shown in fig. 9, (b) is quite similar to that found at $573 \mathrm{~K}$ by Rossnagle and Robinson [17]. They indicate that the compound cone structure arises after the seeds or coatings are eroded by subse bombardment. In fact, our spot surface analysis by EMPA and AES failed to detect molybdenum on these cone-covered copper surfaces. However, a weak indication of molybdenum was found in the SIMS spectra shown in fig. 11. This analysis also found iron and rhromium on both the copper surfaces, with and without cones. These extra impurities may be from some section of the vacuum chamber of the PISCES facility. However, it is deductively clear that the surface modification was not driven by these extra impurities under the present condition. Also, it is found by $\mathrm{X}$-ray diffraction analysis that the sub-surface structure of the cone-covered copper retains the original FCC (Face Centered Cubic) crystalline structure. This is reasonable since the $\mathrm{X}$-ray penetration depth, which is about $25 \mu \mathrm{m}$, is a few orders of magnitude larger than the region where the surface modification is taking place.

Generally, the winding structures are found for copper surfac-s seeded with tungsten at high temperatures. These features are often attributed to a flow or agglomeration of the coating material between adjoining cones [18]. However, the corallike winding structure found on the redeposited 304 SS presented in fig. 10 appears to have 
more complex structure in a tilted view. This clearly indicates a different mechanism. Because of the purr thermal conductivity of 340SS, local tempexatures at sharp tips of seed cones can be apprecialby higher than the bulk temperature. Some quasi-liquid state [18] might be attained. Possible consequences are that these quasi-melted cone tips will bend and evenulilly bridge each other to create the coral-like features. Further investigation reeds to be done to clarify the mechanism. RBS analysis was conducted for redeposited $3045 \mathrm{~S}$ using a $6 \mathrm{MeV} \mathrm{He}^{+}$ion beam. The result indicates that the concentration of molybdenum is about $1 \times 10^{16}$ atoms $\mathrm{cm}^{-2}$ in the surface region with a thickness of about 2 $\mu \mathrm{m}$. Also, the spot analysis by EMPA found molybdenum both on the ridges and in the valleys of the winding structure. The characteristic X-ray spectra are shown in fig 12 . Also, the modified surface at an elevated temperature indicated cbromium enriched composition relative to that for the as-polished surface. However, this is not surprising since stainless steels often segregate chromium at elevated temperatures in vacuum [19]. One difficulty in surface analysis is that seed materials may be largely eroded, once strong surface modification begins.

The substrate temperature is also a key parameter affecting surface modification for a given seed-substrate combination since seeds must migrate via surface diffusion to form an effective impurity cluster or local coating to induce a protuberance [20,21]. This means that the processes of forming such an impurity cluster and erosion of individual seeds under ion bombardment are competitive one another. It follows that there is a critical temperature to trigger the surface texturing for a given seed concentration. Opposite is also sue, namely, the minimum seed concentration exists for a given temperature. The minimum seed concentration has been found to be as small as a few percent of the atomic density of a monolayer [22]. Our EMPA analysis shown in fig. 12 provides us a convincing result of this thermal effect that no molybdenum was indicated on the redeposited $3045 S$ seeded at an ambient temperature. Apparently, the surface diffusion 
was defeated by sputter erosion of seeds in this kinetic competition governing the surface evolution, which resulted in the smooth surface morphology shown in fig.10, (a).

The critical temperature for surface modification of copper by seeding molybdenum has been reported to be $470 \mathrm{~K}$ under Ar ion bombardment with a flux in the order of $10^{16}$ ions $\mathrm{sec}^{-1} \mathrm{Cm}^{-2}$. This critical temperature is somewhat higher than our finding: about $400 \mathrm{~K}$. Unfortunately, the discrepancy in these critical temperatures can not be clearly explained at present. There is a theory claiming that the ion bombardment enhances surface diffusion of impurity atoms [17]. This suggests a possibility that the critical temperature might be lower at a higher ion bombarding flux. Considering the high plasma flux in the present study, the relatively low critical temperature may not be surprising. However, the detail mechänism is still unclear.

In one experiment, the $3045 S$ target, temperaire vas changed from 300 to $650 \mathrm{~K}$ at a ramp-up speed of roughly 30 degrees $\sec ^{-I}$ to witness surface modification starting at the critical temperature. At about 550K, the surfac; morphology suddenly changed, which was visually identified by the color of the target through a viewing port. This sudden change will be theoretically interpreted later in this paper. The resultant modified surface morphology is similar to that shown in fig. 10, (b) and (c).

One remaining question is whether or not the initial surface contaminations such as oxygen and/or carbon, which are always detected by AES surface analysis, can be such an impurity as to induce protruding features. A tentative answer is negative unless there are strongly segregated oxide and/or carbide phases that can meet the requirements for seed maierials. Interestingly, recent measurements [23] have shown a significantly reduced erosion yield for sputter-deposited copper. This was attributed to surfacs chemical compounds such as copper oxides formed during deposition. Fu ther investigation is greatly anticipated in order to clarify this point. 


\section{5-3. MODELING OF IMPURITY DRIVEN SURFACE EVOLUTION}

A simple model is introduced here to describe the surface modification by plasma bombardment although there are other elaborate theories for ion bombardment surface modification[6]. As described in section 3, the surface morphological evolution is driven mostly by physical sputtering under the PISCES plasma Jombardment conditions. Again, simultaneous erosion and redeposition is equivalent to the bombardment of two different ions with the same energy (assuming the same degree of ionization).

The sputtering yjeld is well known to change with angle of ion incidence. This angular dependence is considered to be one of the crucial factors determining the surface modification process. As an example, the angular dependence of the sputtering yields of copper by argon and copper ions is shown in fig. 13. Notice that there is no significant difference in the angular dependence for these two cascs. This suggests that the simultaneous etosion and redeposition of copper under argon plasma bombardment can be simply approximated as ion bombardment at an effective erosion rate given by the theory: AREX deccribed in section 4.

Consider only the longitudinal motion of microscopic points on a material surface being modified by energetic ion bombardment. The longitudinal position, $y$, is expressed as a function of time, $t$, and lateral position, $x$ :

$y(x, t+\Delta t)=y(x, t)-\Delta y(x)$

The recession rate due to the ion bombardment, $\Delta y$, is determined by

$\Delta y(x)=d I Y(\theta) \Delta t$ 
where $d$ is the monolayer thickness of the target material, $I$ is the incident ion flux, and $Y$ is the effective erosion yield as a function of angle of incidence, $\theta$. The angular dependence of the effective erosion yieid can be obtained from a TRIM calculation [11], as shown in fig.13. The product of these two factors is assumed to give a net erosion rate determined by eq.(1). The angle of incidence with respect to the surface normal is equal to the slope of the surface contour and is given by

$\theta(x, t)=\tan ^{-1}[\{y(x+\Delta x, t)-y(x-\Delta x, t)\} / 2 \Delta x]$

At the surface impurity spot, $\mathrm{r}^{\prime}$, the longitudinal recessicn rate is

$\Delta y\left(x^{\prime}\right)=d^{\prime} I^{\prime}(\theta) \Delta t$

where $\mathrm{d}^{\prime}$ and $\mathrm{Y}^{\prime}$ is the monolayer thickness and sputtering yield of the seed material, respectively. The incident angle will be set at zero for an impurity-seeded spot

Another mechanism involved in this model is setrapping of sputtered particles to bury deep valleys between protruding features. This can be simulated by setting the recession rate equal to zero at the bottom point of a steep valley having slopes for which the sputtering yield is zero, In this preliminary version, however, quasi-liquid states are not considered.

As an example, the time evolution of a copper cone seeded with molybdenum under Ar-plasma bombardment was simulated using this model. In this example, the initial surface is assumed to be flat for simplicity. The flux and energy of the Ar-plasma bombardment are set at $1.0 \times 10^{18}$ ions $\sec ^{-1} \mathrm{~cm}^{-2}$ and $100 \mathrm{eV}$, iespectively. The redeposition conditions are assumed to give a net erosion yield of 0.3 normalized to the corresponding sputtering yield. An impurity cluster with a hickness of 300 angstroms is located at the center of the simulated surface: $x=0$. This hypothetical thickness of the 
impurity cluster was set such that the seed material will be eroded in the course of simialation.

The result is shown in frg. 14. One can realize that the growth of the mol; bdenumseeded cone is quite rapid under thcse conditions. This is consistent with our experimental finding of the sudden change of the surface morphology of 304SS induced by seeding molybdenum at an elevated temperature. Also, a compound cone structure such as that shown in fig. 9, (b) is theoretically fcund after the seed marerial is eroded. These results indicate that this first-order modeling can be at least qualitatively compared with the present experimental data.

\section{FUSION RELATED SURFACE PROPERTIES OF RFDEPOSITED MATERIALS}

\section{6-1. SPUTTERING YIELD OF REDEPOSITED MATERIAL}

The strongly modified surface morphologies with a coral-like winding structure (fig. 10, (b) and (c)) and densely populated, tall cone structure (fig 9, (b)) indicate a possibility that sputtered particles can be retrapped within these surface features. In orcer to cneck this possibility, the sputtering yield of redeposited copper with cones was measured using a deuterium $\left(D^{+}\right)$ion beam at an energy of $200 \mathrm{eV}$. As shown in fig. 15 , the resultirt' sputtering yield of copper with cones was found to be reduced by a factor of two relative to that with a smooth surface. Recently, Auciello reviewed both experimental and theoretical studies on the retrapping behavior of textured surfaces [24]. It was pointed out that the sputtering yield of a surface with densely populated cones is likely to be reduced, particularly in the low energy range from 200 to $4000 \mathrm{eV}$. This is quite consistent with our experimental finding of the reduced sputtering yield of redeposited cc pper with molybdenum seeded cones. 
As a first-order attempt, the theory: AREX was modified such that the modified surface has a $50 \%$ reduced sputtering yield. The result is shown by a dotted line in fig. 5 . Apparently, the observed discrepancy between the theory and experimental data is compensated by this modification. However, further investigation needs to be done, given the scatter in the experimental points.

It is of considerable importance to note here that a decade ago, an artificial honeycomb structure was once proposed and demonstrated as a surface texture for first - walls to minimize material erosion[25, 26]. The experimental findings mentioned above clearly indicate a possibility that one may expect a "natural honeycomb structure" on surface components of an operating fusion device.

\section{6-2. DEUTERIUM REEMISSION, RETENTION AND PLASMA DRIVEN PERMEATION}

From a practical engineering point of view, of great interest is to investigate fusion related characteristics of redeposited materials with strongly modified surface morphologies. Detuterium reemission, retention and plasma driven permeation were measured for redeposited $304 S S$ with a coral-like surface structure. The techniques for these measurements are described in detail elsewhere[27,28,29].

The surface roughness of the redeposited 304 SS was quantified by the BET ( Brunauer, Emmett, Teller) method. The result indicated increased surface area for the redeposited 304SS by a factor of about 10 , which in turn is similar to that for the surface modified by helium blisters [30].

The deuterium reemission measurement was conducted at an ambient temperature using a $6 \mathrm{kVV} \mathrm{D}^{+}{ }_{3}$ beam with a flux of $2 \times 10^{14} \mathrm{D} \mathrm{sec}^{-1} \mathrm{~cm}^{-2}$. The targets were first bombarded up to a fluence in the order of $10^{18} \mathrm{D} \mathrm{cm}^{-2}$ until a reproducible reemission 
response was observed during beam-on/off cycles. Because of the small sputtering yield for deuterium, the surface modification during this pre-treatment process is negligible compared with the original modification. The result of reemission measurements is shown in fig. 16. Deuterium reemission from redeposited stainless steel is increased by a factor of 2 relative to as-received materials under identical conditions. Also, the rise and decline of reemission for the redeposited target is somewhat faster than those for as-received materials. This behavior is quite similar to the case when the surface is deliberately roughened before ion implantation [27].

At temperatures below $370 \mathrm{~K}$, deuterium reemission is generally controlled by solid-state diftusion kinetics [27]. Because of the strongly modified surface, a significant frastion of incident deuterium ions impinge on the target at grazing angles in the coral structures. Therefore, the depth cistribution of implanted ions for the madified surface is considered to be effectively shallower than that for a flat surface. It follows that the diffusion length required to release deuterium is short, which results in an increase in the reemission ratio.

Using the NRA method [28] based on the reaction, $\mathrm{D}\left({ }^{3} \mathrm{He}, \mathrm{p}\right)^{4} \mathrm{He}$, deuterium retention in the near surface region (about $1 \mu \mathrm{m}$ below surface) was measured after inplantations up to a fluence of $10^{18} \mathrm{D} \mathrm{cm}^{-2}$. The result showed deuterium concentrations of $3 \times 10^{16}$ and $8 \times 10^{15} \mathrm{D} \mathrm{cm}^{-2}$ for the near surface region with a depth of about $1 \mu \mathrm{m}$ of the redeposited and as-received naterials, respectively. This result implies that a strongly modified surface tends to reflect the bombarding particles because of the grazing angle of incidence.

Plasma driven permeation of deuterium through redeposited 304SS was measured at 823K using the TPX (Tritium Permeation Experimental) facility [29]. The modified surface was placed facing the deuterium plasma. The plasma bombardment current density was $0.5 \mathrm{n}^{\prime} \mathrm{A} \mathrm{\textrm {cm } ^ { - 2 }}$. The sample was set at $25 \mathrm{~V}$ negative to the plasma so as not to make further surface modification due to sputtering by the deuterium plasma bombardment 
during permeation measurement: The result obtained is shown in fig. 17. The steady state permeation rate through the redeposited material was found to be reduced by a factor of 2 to 3 relative to the as-received material. In this temperature range, deuterium reemission is generally controlled by molec lar recombinaticn at the surface. Therefore, it can be concluded that the decrease in the steady state permeation rate is due to the in:reased surface area which in turn leads to an increase in deuterium desorption in the upstream. The reduction of plasma driven permeation is favorable for fusion engineering from a tritium handling safety point of visw.

\section{CONCLUSIONS}

Surface modification of materials by continuc us plasma bombardment has been investigated under simultaneous erosion and redeposition conditions. The mechanism of redeposition is analyzed to evaluate the net erosion yield. The erosion rate due to the plasma bombardment significantly decreases, when redeposition occurs, so long as the self-sputtering yield is smaller than the particle trapping coefficient. The morphology of the surface subject to simultaneous erosion and redeposition is found to be similar to that of an ordinary sputter-etched surface. Also, the refeposited material indicates essentially the same sputtering yield as a bulk material. However, the presence of impurities can significantly modify the surface morphology and sputtering behavir $r$. The mechanism of impurity-induced surface evolution is theoretically elucidated. Also, the critical temperature for impurity-induced surface modification is found to be about $400 \mathrm{~K}$ arid $550 \mathrm{~K}$ for copper and 304 stainless steel, respectively. Jitrongly modified surface morphologies resutt in a reduction of the sputtering yield by the subsequent ion bombardment. Due to the increased surface area of a modified surface lead to an increase in gas reemission and hence a decrease in plasma driven permeation. 
Of particular importance to the fusion community is the finding that plasma interactive surfaces can be strongly modified by foreign impurities transportej from different components. A "natural honeycomb ștructure" to reduce the erosion rate as well as ritium permeation can be developed in an operating fusion device. However, properies of redeposited surfaces investigater in the present work migit be different from those of coating-like deposits. Frrther invest: ation is necessary to understand the nature of surfaces redeposited differently.

\section{ACKNOWLEDGEMENT}

The X-ray diffraction analysis by L.Keller is gre.tly appreciated. The authors wist to acknowledge the technical support by T.Sketchley and V.Low. Special thanks go to K.Andrews for his dedicated work on the computer data acquisition system of the PISCES facility. This work is supported by the United States Department of Energy, Office of Fusion Energy under contract \#DE-AT03-84ER52104. 
Table 1. Experimental Parameters for Typical Redeposition Conditions.

\begin{tabular}{lll}
\hline Parameters & Copper & 304 SS \\
\hline Ion Bombardment Energy(eV) & 100 & 100 \\
Sputtering yield(atoms ion $\left.{ }^{-1}\right)$ & 0.43 & 0.21 \\
Self-sputtering yield(atoms ion ${ }^{-1}$ ) & 0.395 & 0.188 \\
Particle reflection coefficient & 0.197 & 0.213 \\
Ion Flux(Ar' sec-1 $\left.\mathrm{cm}^{-2}\right)$ & $1.5 \times 10^{18}$ & $1.0 \times 10^{18}$ \\
Electron teniperature(eV) & 10.6 & 15.5 \\
Electron Density $\left(\mathrm{cm}^{-3}\right)$ & $5.96 \times 10^{12}$ & $3.11 \times 10^{12}$ \\
Mean Free Path $\left(\mathrm{cm}^{-3}\right)$ & 1.49 & 1.46 \\
\hline
\end{tabular}




\section{REFERENCES}

[1] D.E.Post and R.Behrisch, Physics of Plasma-Wail Interactions in Controlied Fusion, Plenum Press (1986).

[2] Y.Hirooka, D.M.Goebel,W.K.Leung, G.A.Campbell and R.W.Conn, to be published in J.Nucl. Mater,(presented at 2nd Int.Conf.Fusion Reactor Materials, Chicago, 1986).

[3] D.M.Goebel, G.A.Cumpbell and R.W.Conn, J.Nucl.Mater, 121(1984)277.

[4] D.M.Goebel and R.W.Conn, J.Nucl.Mater. 128 \& 129(1984)249.

[5] R.Behrisch, Sputtering by Particle Bombardment, Vols. 1\&2, Springer-Verlag Berlin Heigelberg (1981 \& 1983).

[6] O.Auciello and R.Kelly, Ion Bombardment Modification of Surfaces, Elsevier Science Publishing(1984).

[7] R.A.Langley, J.Bohdansky, W.Ecstein,P.Mioduszewski,J.Roth, E.Taglauer, E.W.Thomas and H.Verbeek, K.L.Wilson, Nucl.Fusion Spec.Issue 1984.

[8] For example, P.Staib, H.Kukral, E.Glock and G.Staudenmaier, J.Nucl.Mater. i $11 \& 112$ (1982) 173.

[9] N.Matsunami, Y.Yamanura, Y.Itikawa, N.Itoh, Y.Kazumata, S.Miyagawa, K.Morita, R.Shimizu and H.Tawara, Atom.Data and Nucl. Data Tables 31(1984)1. [:0] W.Lotz, Z.Physik 206(1967)205.

[11] J.P.Biersack and L.G.Haggmark, Nucl.Instr. \& Methods, 121(1980)257.

[12] INTOR Rcport Phase-1, IAEA(11983).

[13] For example, E.Vietzke, K.Flaskamp and V. Philipps, J.NucI.Mater. 111(1982)763.

[14] W.D.Langer, Nucl. Fusion 22(1982)751.

[15] D.M.Goebel, Y.Hirooka, R.W.Conn,W.K.Leung, J.Bohdansky, K.L.Wilson, W.Bauer, R.A.Causey, A.E.Pontau, A.R.Krauss, D.M.Gruen, and MH.MendeIsohn, to be pulblished in I.Nucl.Mater. (presented at 7th Int.Conf. Plasma Surface Interactions, Princeton, 1986.). 
[16] G.K.Wehner, J.Vac.Sci.\&Technol-A, 3(1985)1821.

[17] S.M.Rossnagel and R.S.Rosinson, J.Vac.Sci.Technol. 21(1982)790.

[18] S.M.Rossnagel and R.S.Rosinson, J.Vac.Sci.Technol, 20(1982)506.

[19] A.Mathewson and M.H.Acjard, Proc.7th Int.Vacuum Congr. and 3rd Int. Conf.Solid Surfaces, Vol.2, Vienna (1977) 1217.

[20] S.M.Rossnagel and R.S.Rosinson, J.Vac.Sei.Technol. 20(1982)195.

[21] H.Kaufman and R.S.Robinson, J.Vac.Sci.Technol. 16(1979)175.

[22] S.M.Rossnagel and R.S.Robinson, Rad.Eff.Lett. 58(1981)11.

[23] B.Bastasz, R.A.Kerst and R.A.Causey, J.Nucl.Mater. 122\&123(1984)1421.

[24] O.Auciello, Rad.Effects 60(1982)l.

[25] S.N.Cramer and E.M.Oblow, Nucl.Fusion115(1975)339.

[26] K.Ohta, H.Maeda, S.Yamamoto, M.Nagai, H.Ohtsuka, S.Kasai, Kodajima,

H.Kinuma, S.Sengoku and Y.Shimonura, J.Nucl.Mater. 76(1987)489.

[27] K.L.Wilson and M.I.Baskes, J.Nucl.Mat. $111 \& 112(1982) 622$.

[28] A.E.Pontau, M.I.Baskes,K.L.Wilson , L.G.Haggmark, J.Bohdansky,

B.M.U.Scherzer and J.Roth, J.Nucl.Mat. 111\&112(1982)651.

[29] R.A.Causey, R.A.Kerst and B.E.Mills, J.Nucl.Mater. 122\&123(1984)1547.

[30] K.L.Wilson, A.E.Pcitau, L.G.Haggmark M.I.Baskes, J.Bohdansky and J.Roth J.Nucl.Mater. 111\&112(1982)622. 


\section{FIGURE CAPTIONS}

Fig. 1: A schematic diagram of the experintental arrangement.

Fig. 2: A typical ion implantation profile calculated by the Monte Calro program : TRLM [11]. In this case, $\mathrm{Ar}^{+}$and $\mathrm{Cu}^{+}$ions with an energy of $100 \mathrm{eV}$ are assumed to be impinging on $\mathrm{Cu}$.

Fig. 3: Calculated ionization mean free paths for physically sputtered copper and iron under a typical plasma bombardment condition with an Ar ion: flux of $1.0 \times 10^{18}{\text { ions } \mathrm{sec}^{-1}}^{-1}$ $\mathrm{cm}^{-2}$.

Fig. 4: Calculated probability of redeposition of materials in the PISCES-facility.

Fig. 5: Comparison of the theory: AREX and experimental data of the net erosion yield as a function of first ionization mean free path. The theory curve represented by a solid line assumes no retrapping effect and the curve represented by a dotted line assumes $50 \%$ reduced sputtering yield due to a topographical retrapping effect (see text).

Fig. 6: Surface evolution of copper during Ar-plasma bombardment with an ion flux of $1.5 \times 10^{18}$ ions $\mathrm{sec}^{-1} \mathrm{~cm}^{-2}$ under a simultaneous erosion and redeposition condition. The total ion fluences are: $4.53 \times 10^{19}$ ions $\mathrm{cm}^{-2}$ for (a), $9.33 \times 10^{19}$ ions $\mathrm{cm}^{-2}$ for (b), $2.8 \times 10^{21}$ ions $\mathrm{cm}^{-2}$ for (c), $9.06 \times 10^{20}$ ions $\mathrm{cm}^{-2}$ for (d) , $1.81 \times 10^{21}$ ions $\mathrm{cm}^{-2}$ for (e), and $4.4 \times 10^{22}$ ions $\mathrm{cm}^{-2}$ for (f).

Fig. 7: Surface evolution of 304 stainless steel during Ar-plasma bombardment with an ion flux of $1.0 \times 10^{18}$ ions $\mathrm{sec}^{-1} \mathrm{~cm}^{-2}$ under a simultaneous erosion and redeposition condition. The total ion fluences are: $2.94 \times 10^{20}$ ions $\mathrm{cm}^{-2}$ for (a), $6.11 \times 10^{20}$ ions $\mathrm{cm}^{-2}$ for (b), $1.14 \times 10^{21}$ ions $\mathrm{cm}^{-2}$ for (c), and $2.81 \times 10^{22}$ ions $\mathrm{cm}^{-2}$ for (d).

Fig. 8: The weight loss of the target as a function of total ion fluence.

Fig. 9: Surface morphologies of copper bombarded by Ar-plasma doped with molybdenum seeds at an ambient temperature (a) and elevated temperature (b).

Fig. 10: Surface morphologies of 304 stainless steel bombarded by Ar-plasma doped with molybdenum seeds at an ambient temperature (a) and elevated temperature: an overhead view (b) and a 30 degree tilted view (c).

Fig. 11:Typical SIMS spectra from copper with (bottom) and without (top) seed-cones.

Fig. 12: Typical EMPA spectra from 304 stainless steel with a relatively smooth surface (seeded at about $300 \mathrm{~K}$ ) and a cotal-like winding structure (seeded at about $510 \mathrm{~K}$ ). Also, the spectra for as-seceived material are shown (top) for comparison.

Fig. 13: The normalized sputtering yield of copper by $100 \mathrm{eV} \mathrm{Ar}+$ and $\mathrm{Cu}^{+}$as a function of angle of incidence. Calculated sputtering yields by the TRIM code [11] are normalized to that for the normal incidence. 
Fig. 14: A simulation of the surface contour evolution of copper with molyboienum seeds during Ar-plasma bombardment under simultaneous erosion and redeposition.

Fig. 15: The sputtering yield of redeposited copper. The closed square symbois represent the data from copper with a cone-covered surface and open square symbols tepresent those from copper with a smooth surface.

Fig. 16: Deuterium reemission from redeposited 304 stainless steel with a modified surface morphology (a coral-like structure).

Fig. 17: Plasma driven permeation of deuterium through redeposited 304 slainless steel with a modified surface morphology (a coral-like structure). 


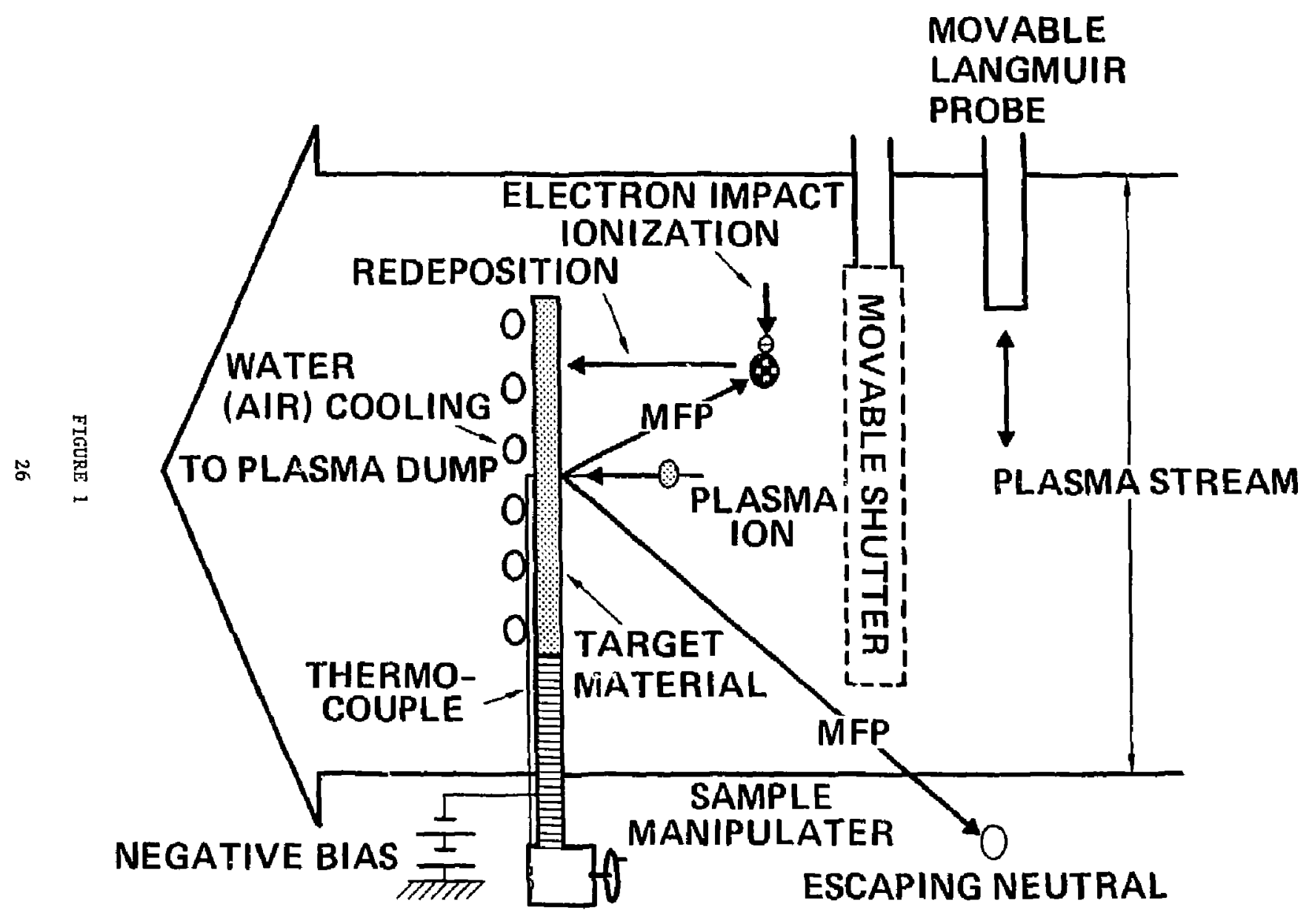




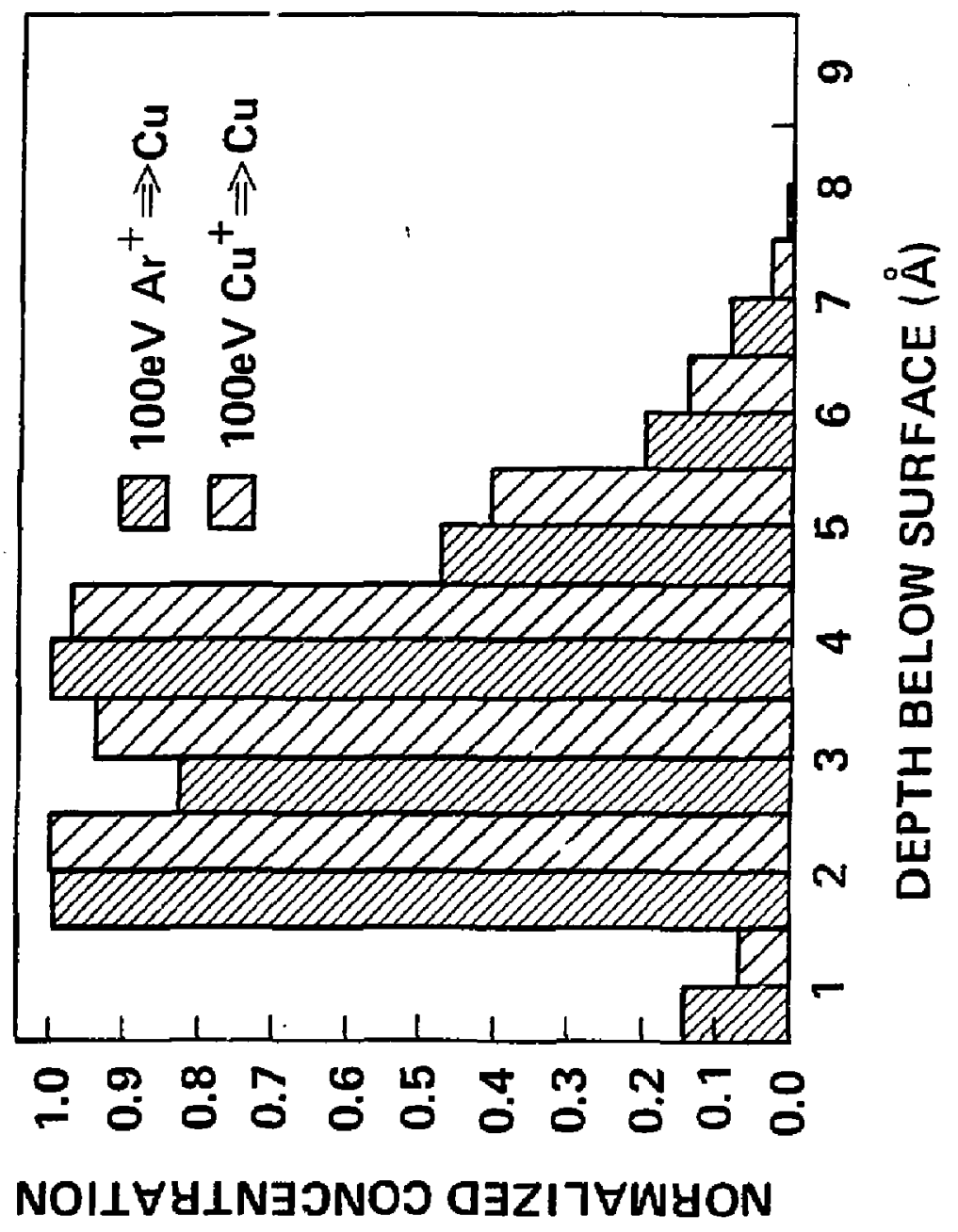

F IGURE 2 


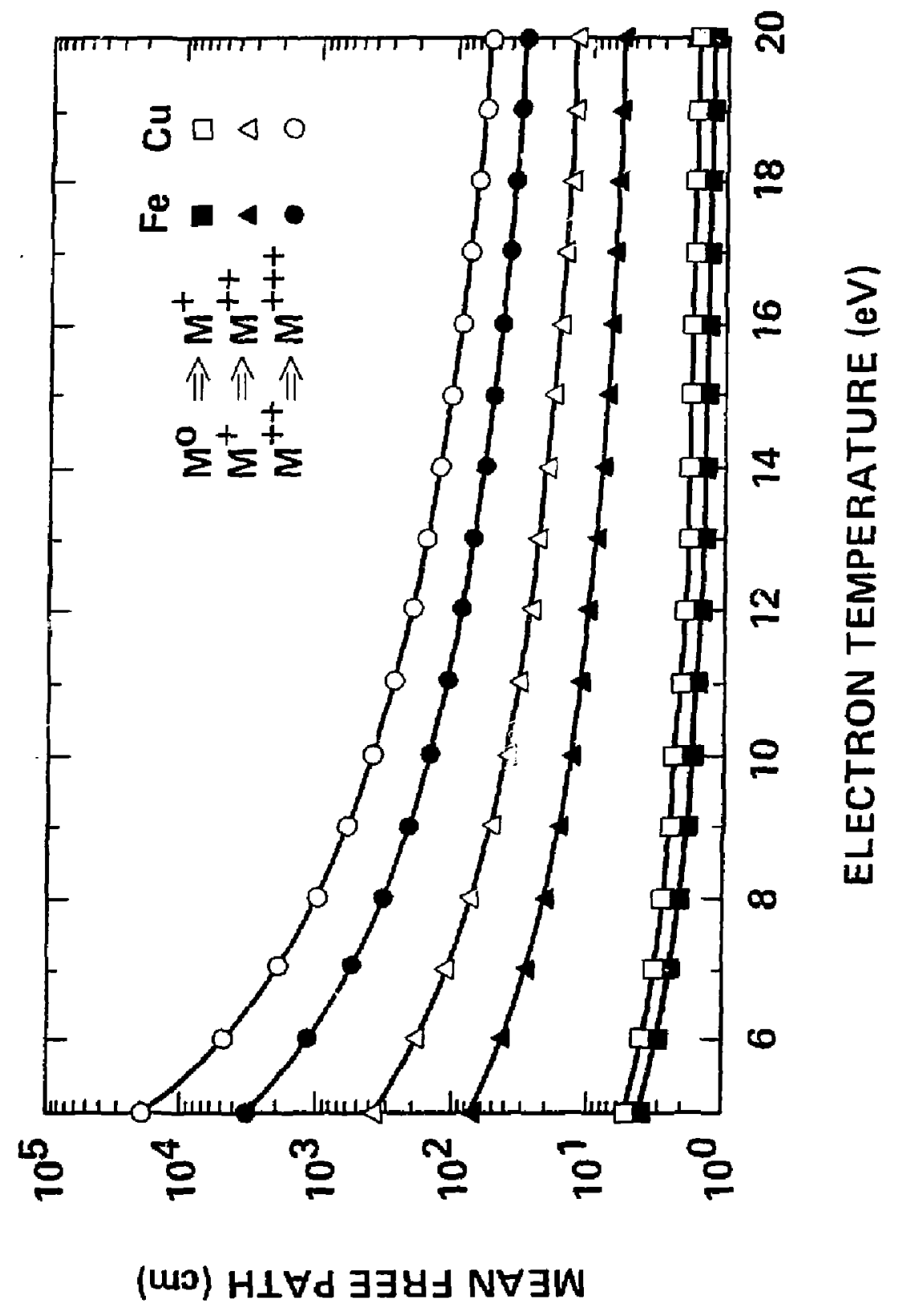

FIGURE 3 


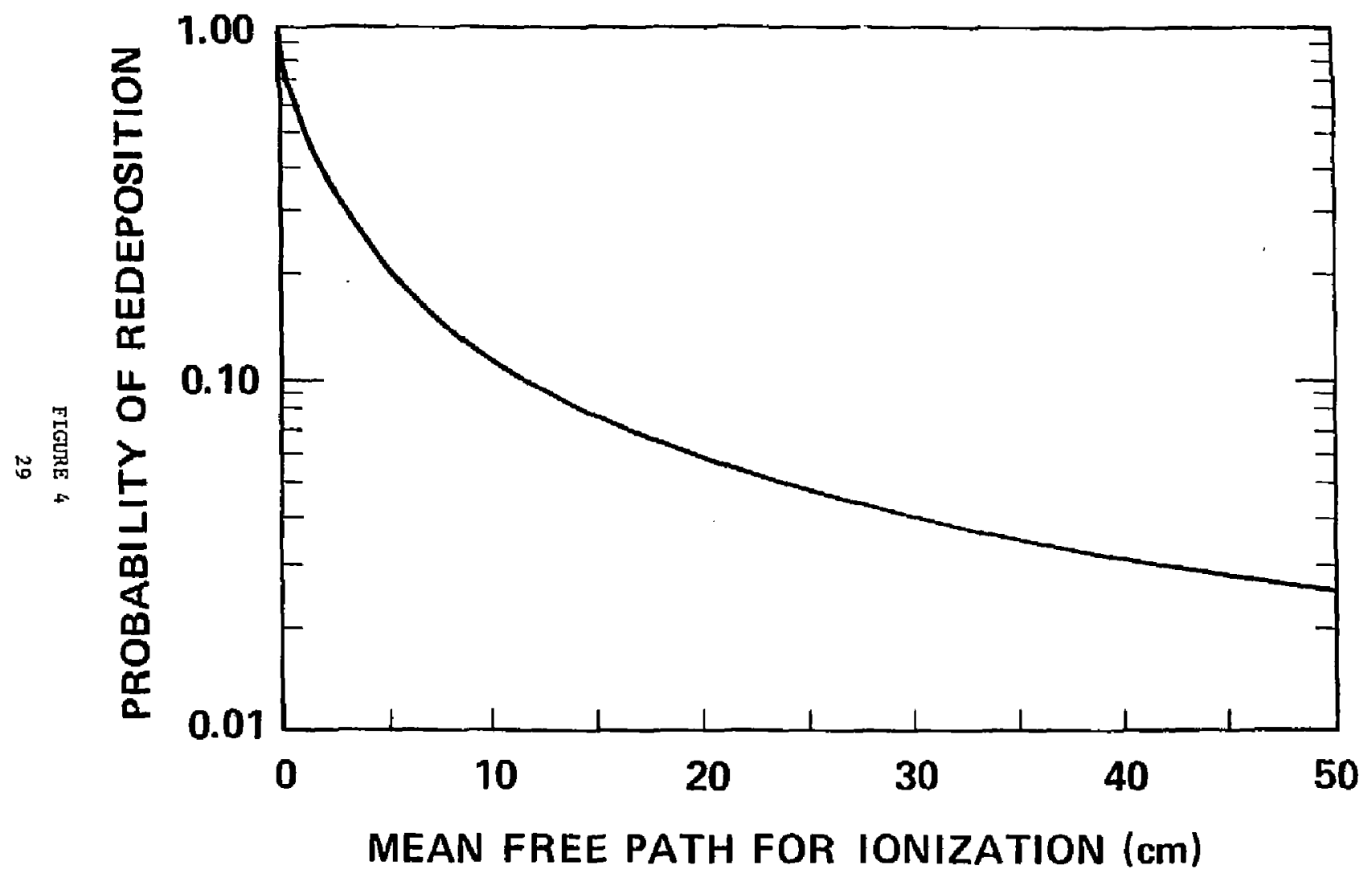




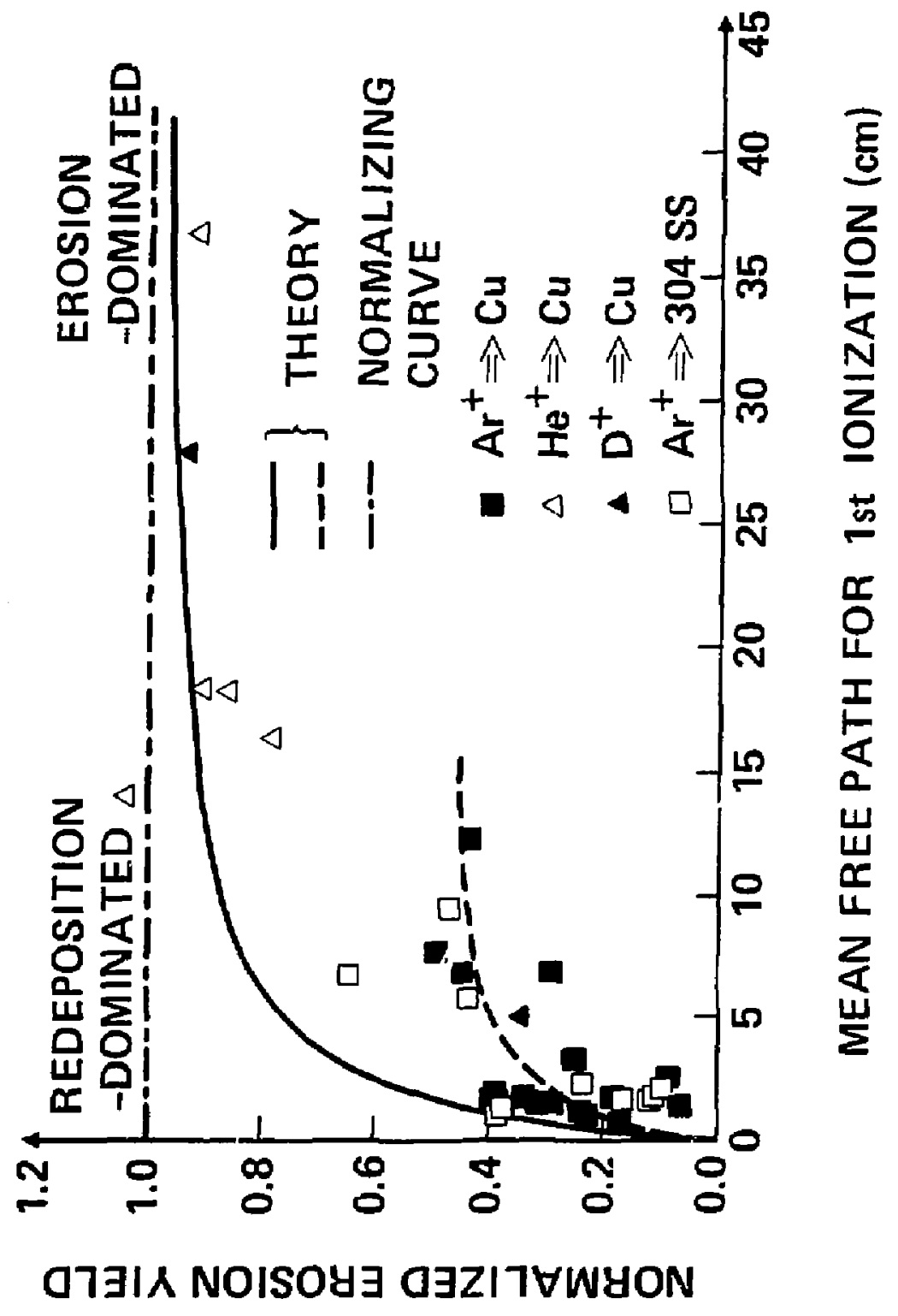

FIGURE 5 


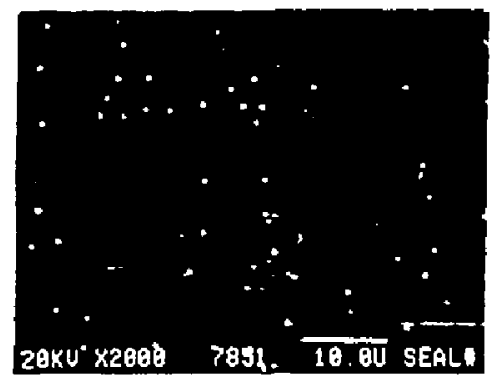

(a)

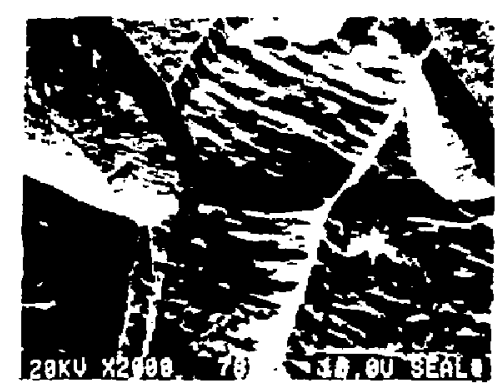

(c)

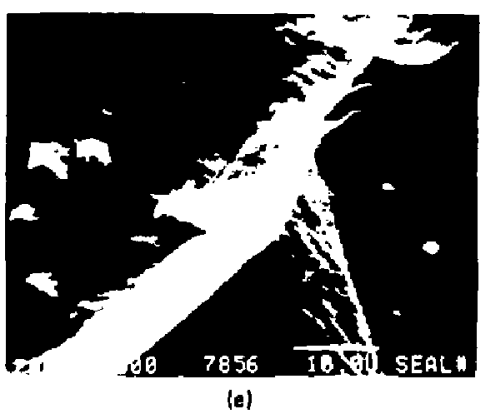

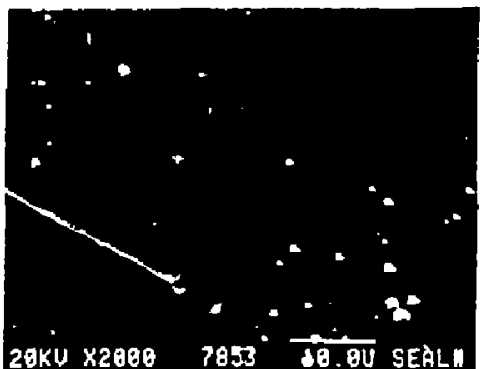

(b)

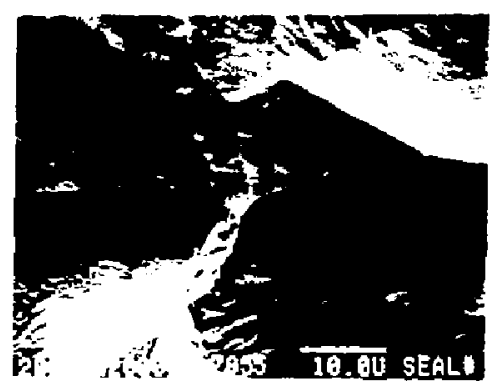

(d)

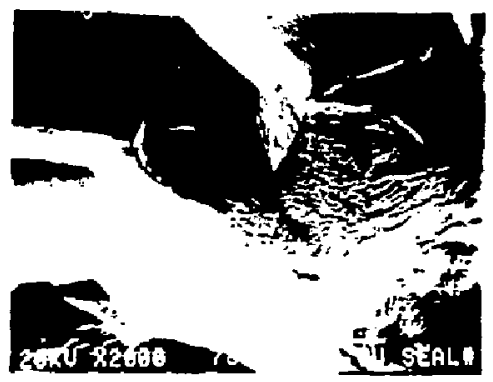

(f)

FIGURE 6 

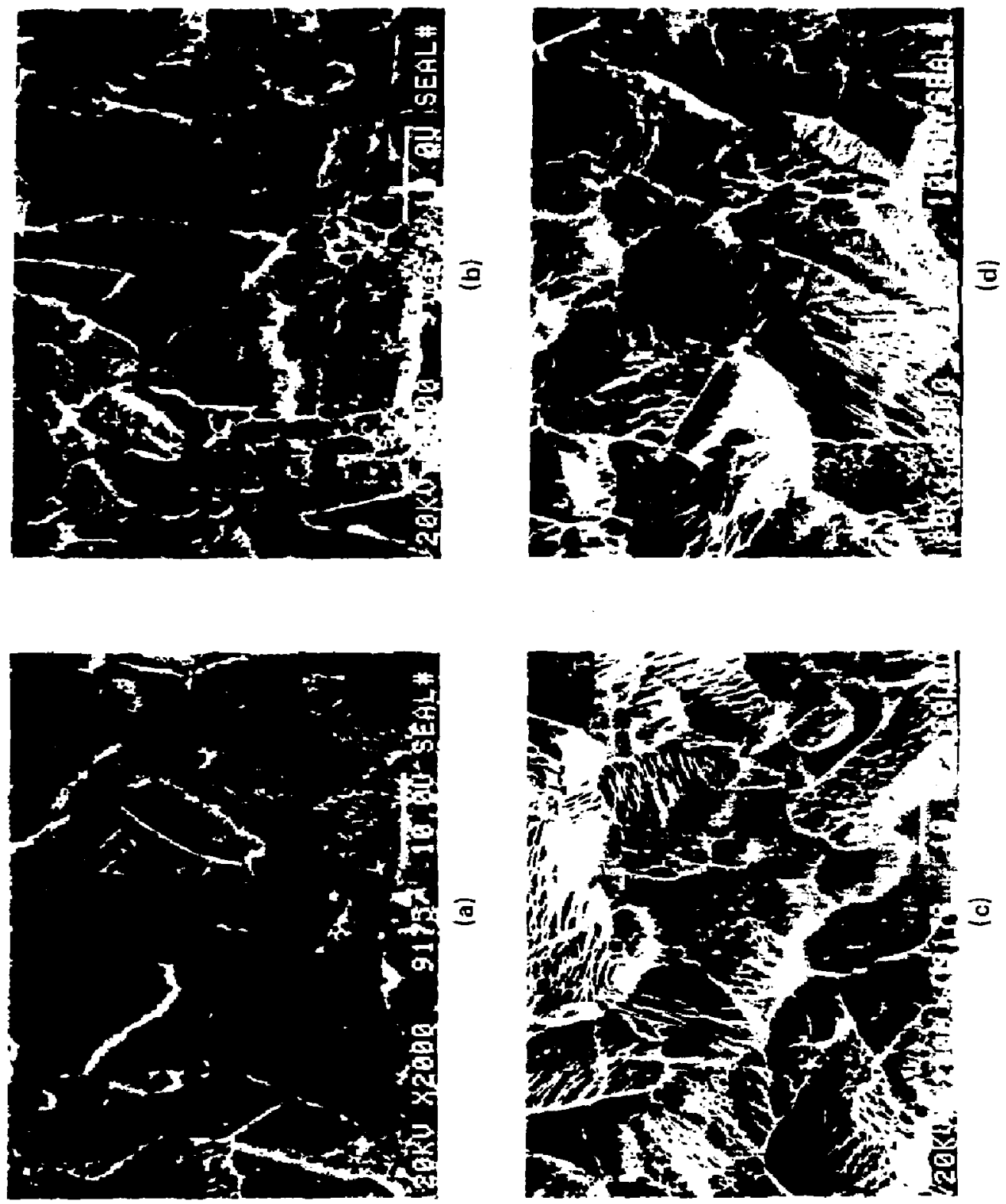

FIGURE ? 


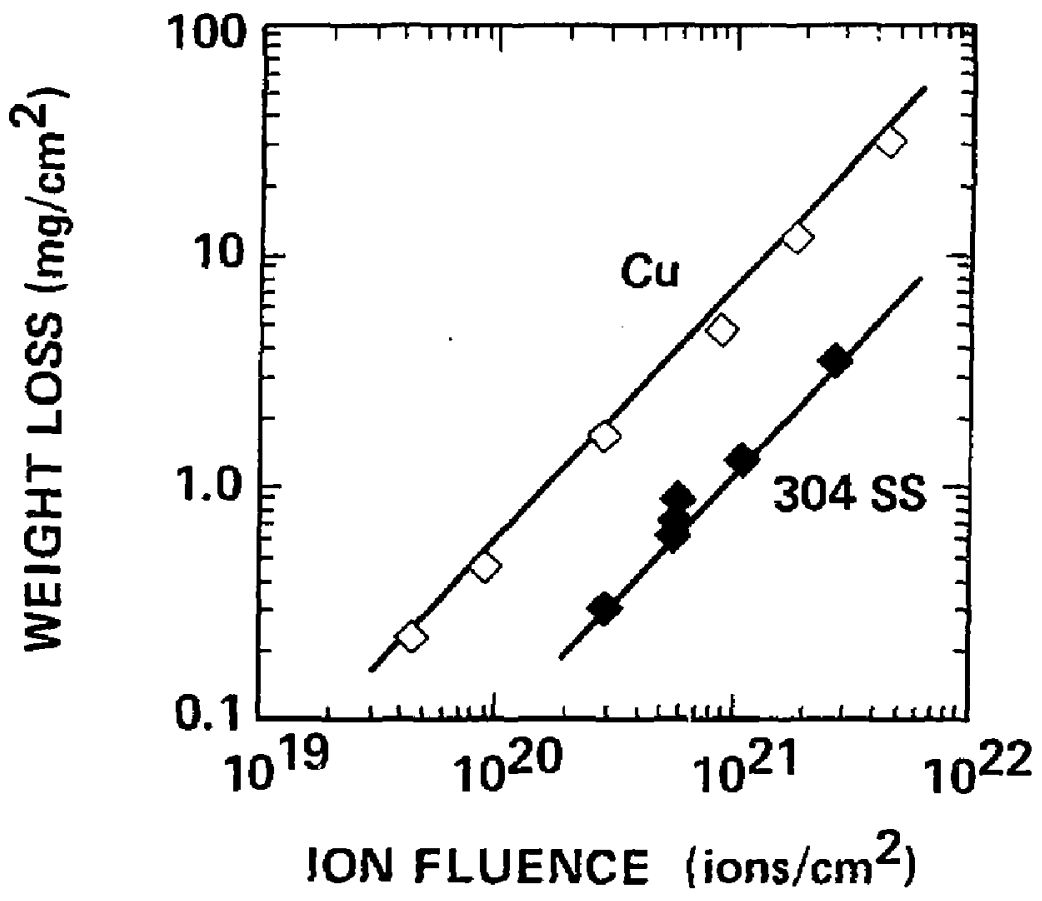

FIGURE 8 
Dex:

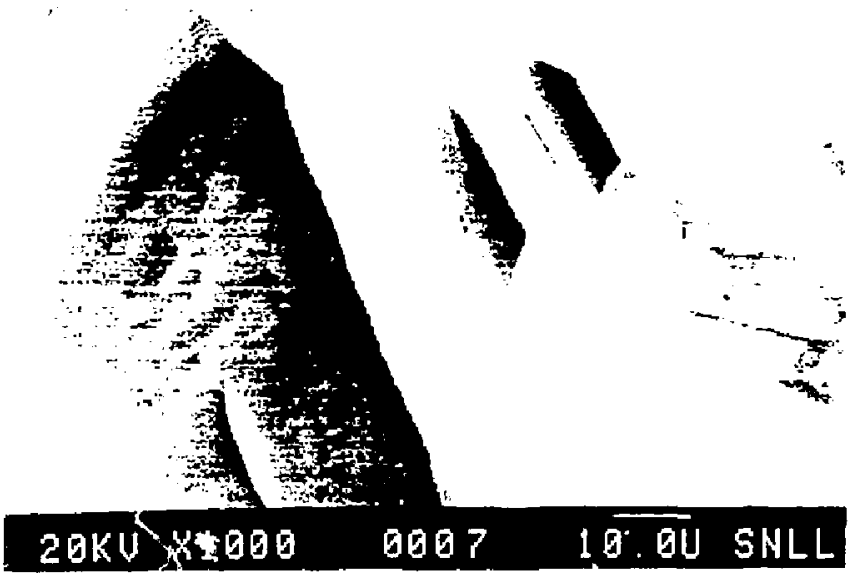

(a)

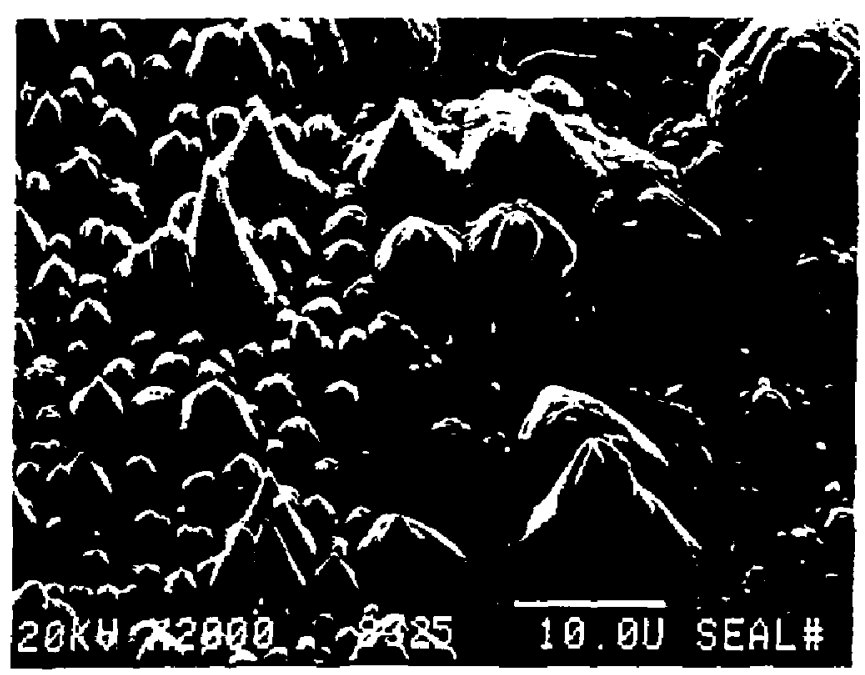

(b)

FIGURE 9 


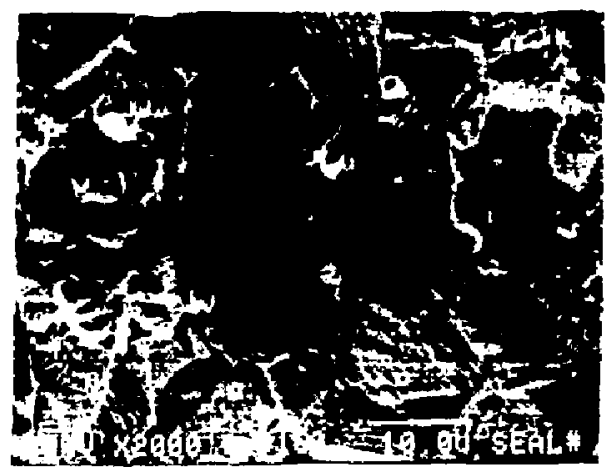

(a)

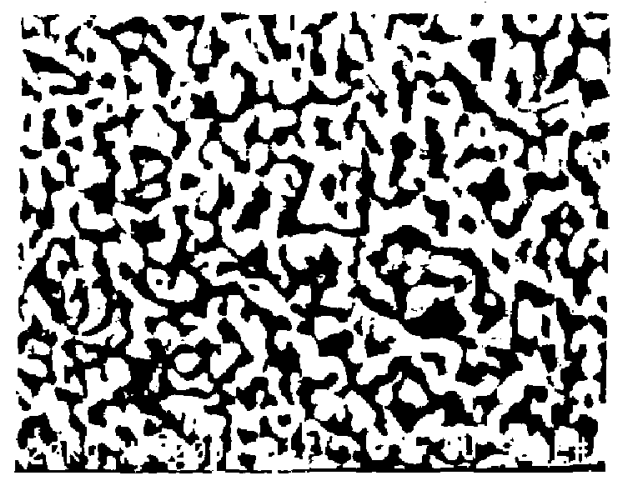

(b)

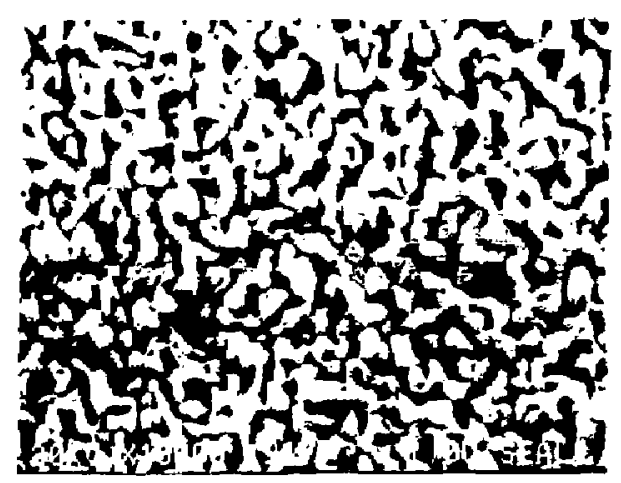

(c)

FIGURE 10 


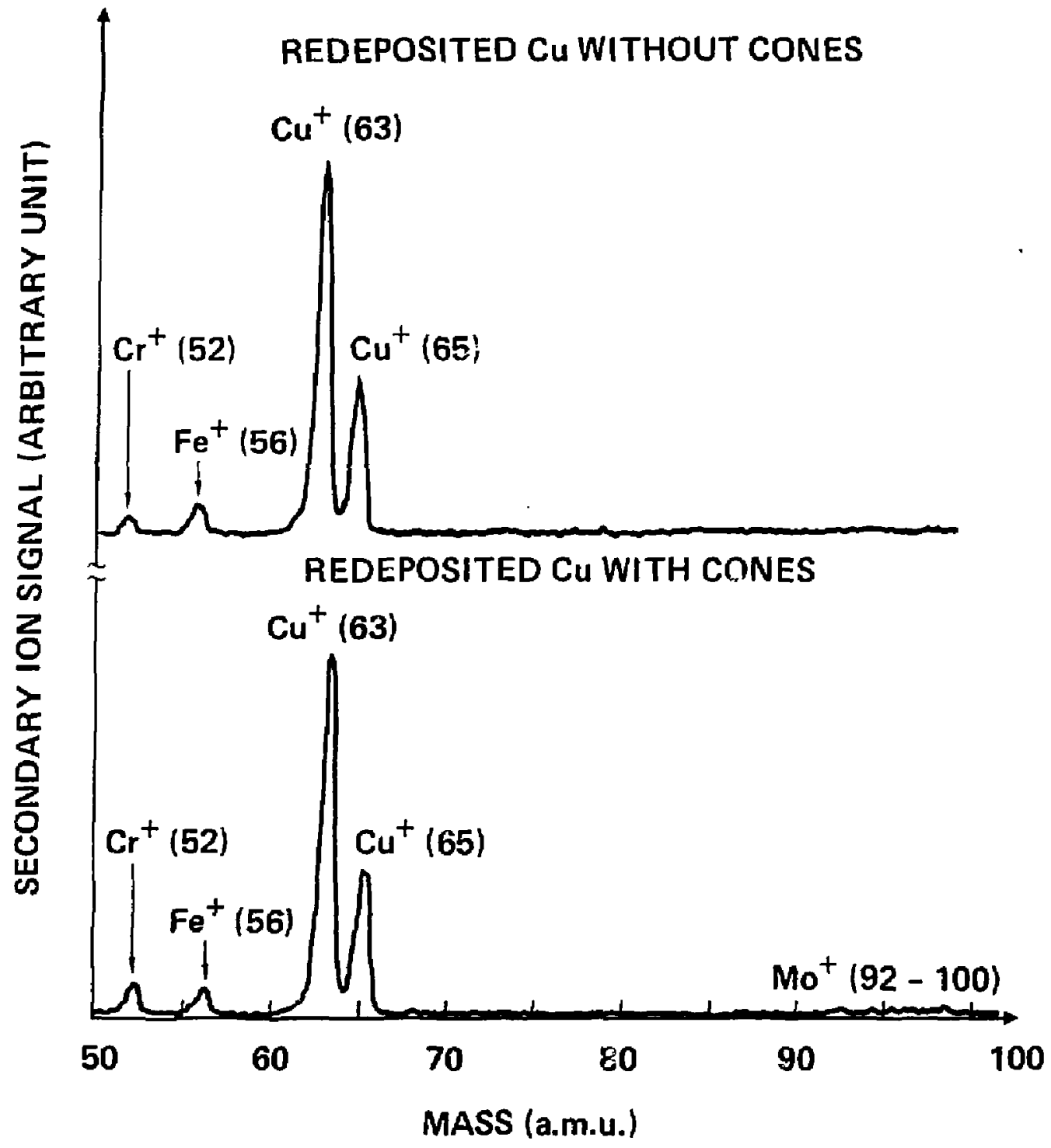

FIGURE 11 


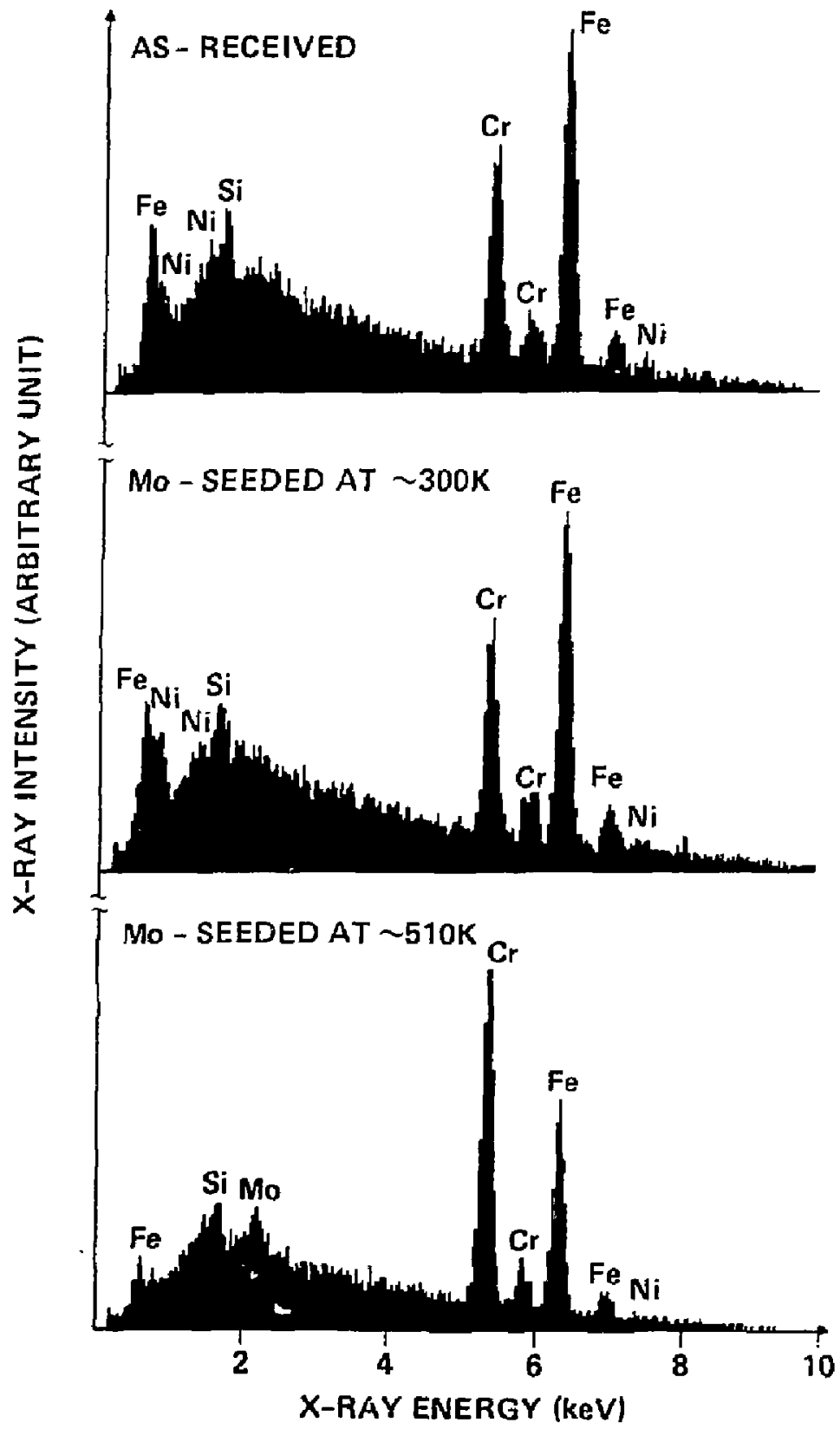

FIGURE 12 


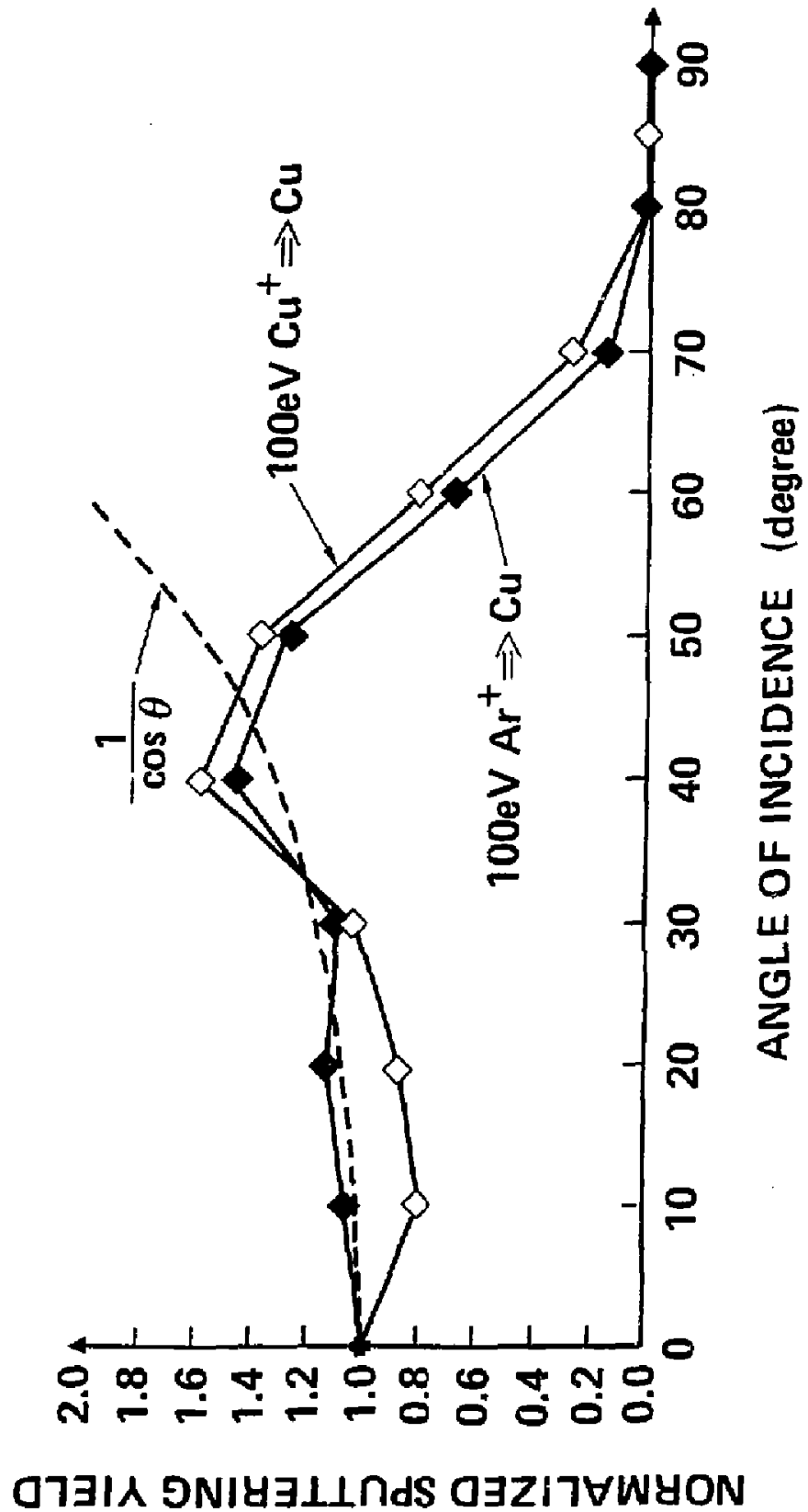

FIGURE 13 


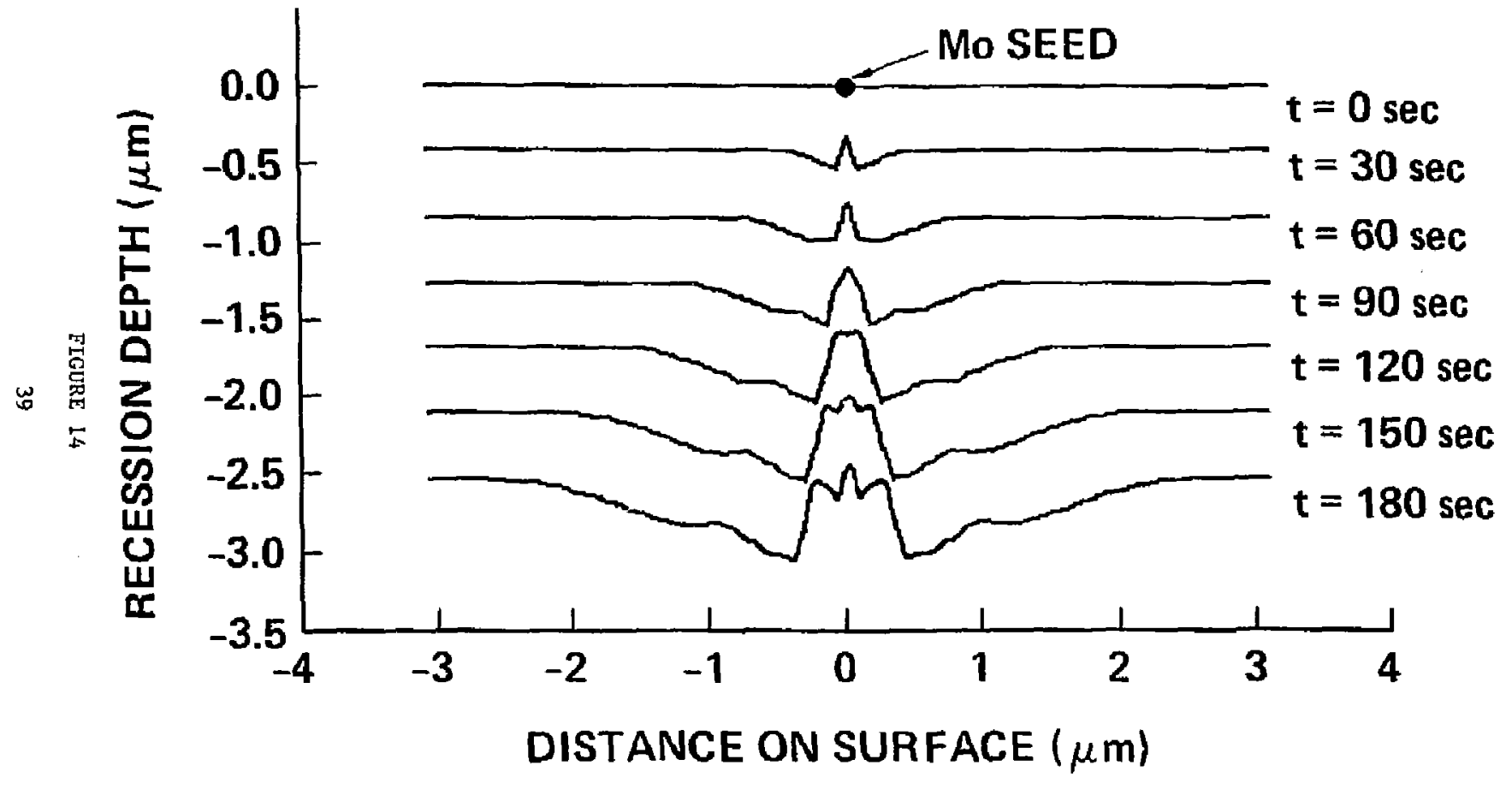




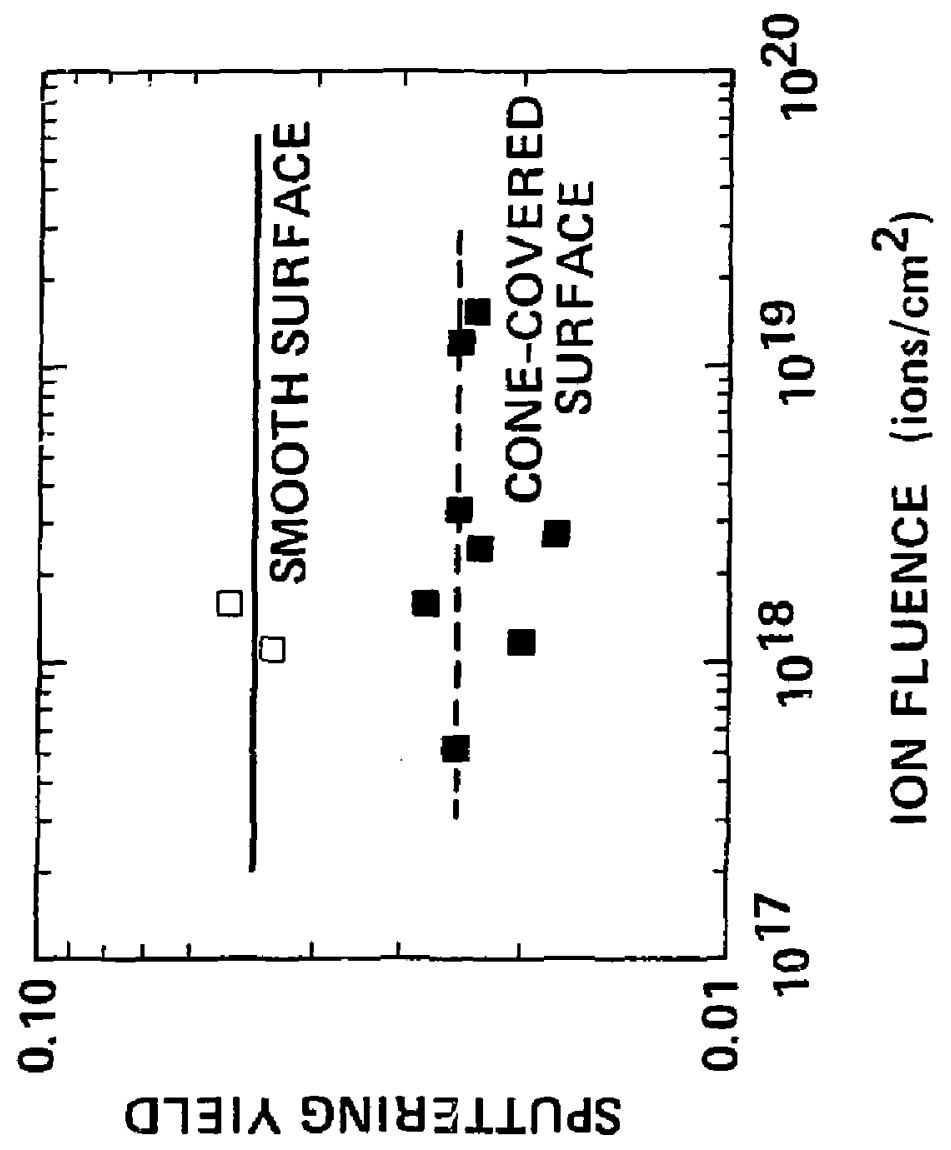

FIGURE 15 


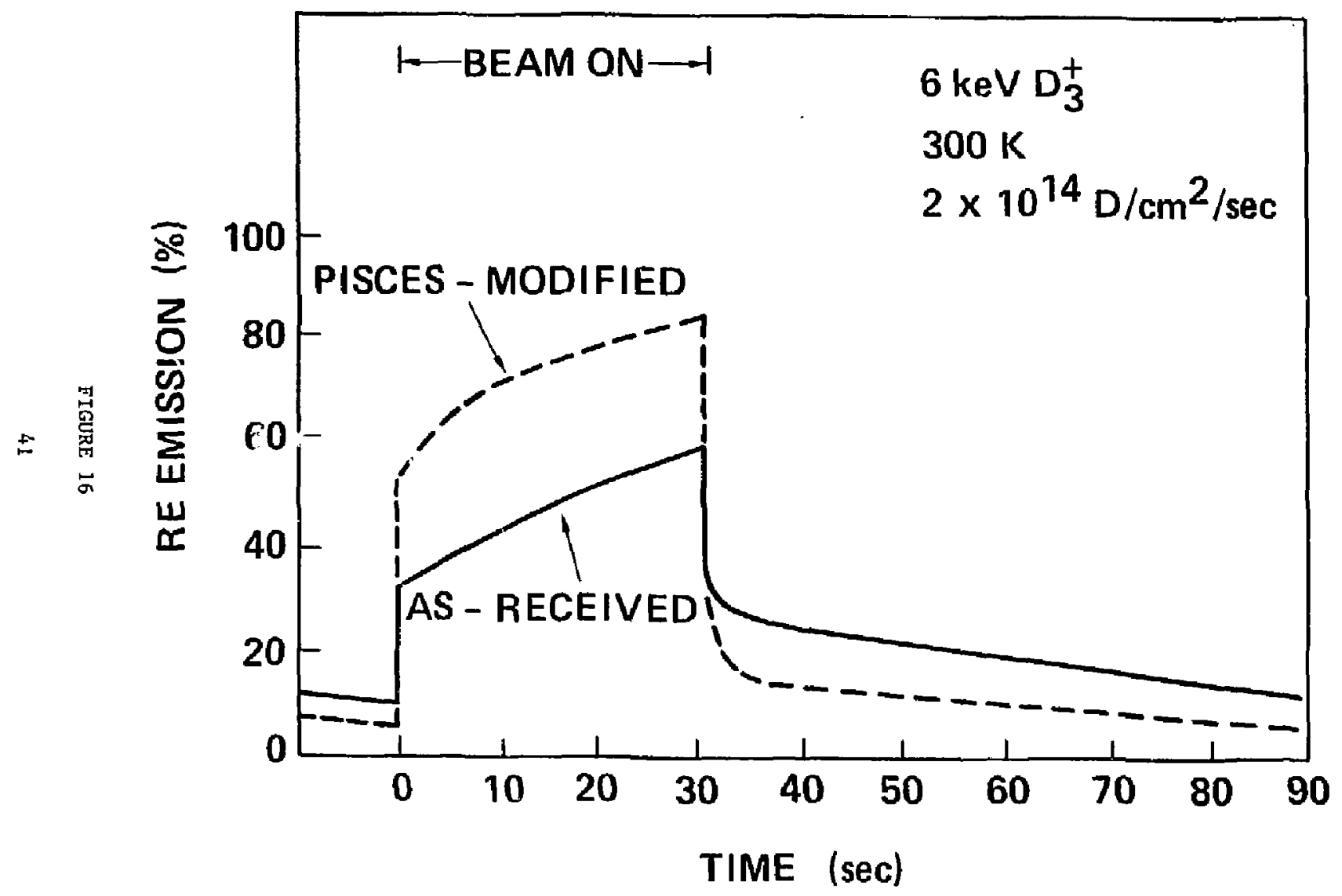




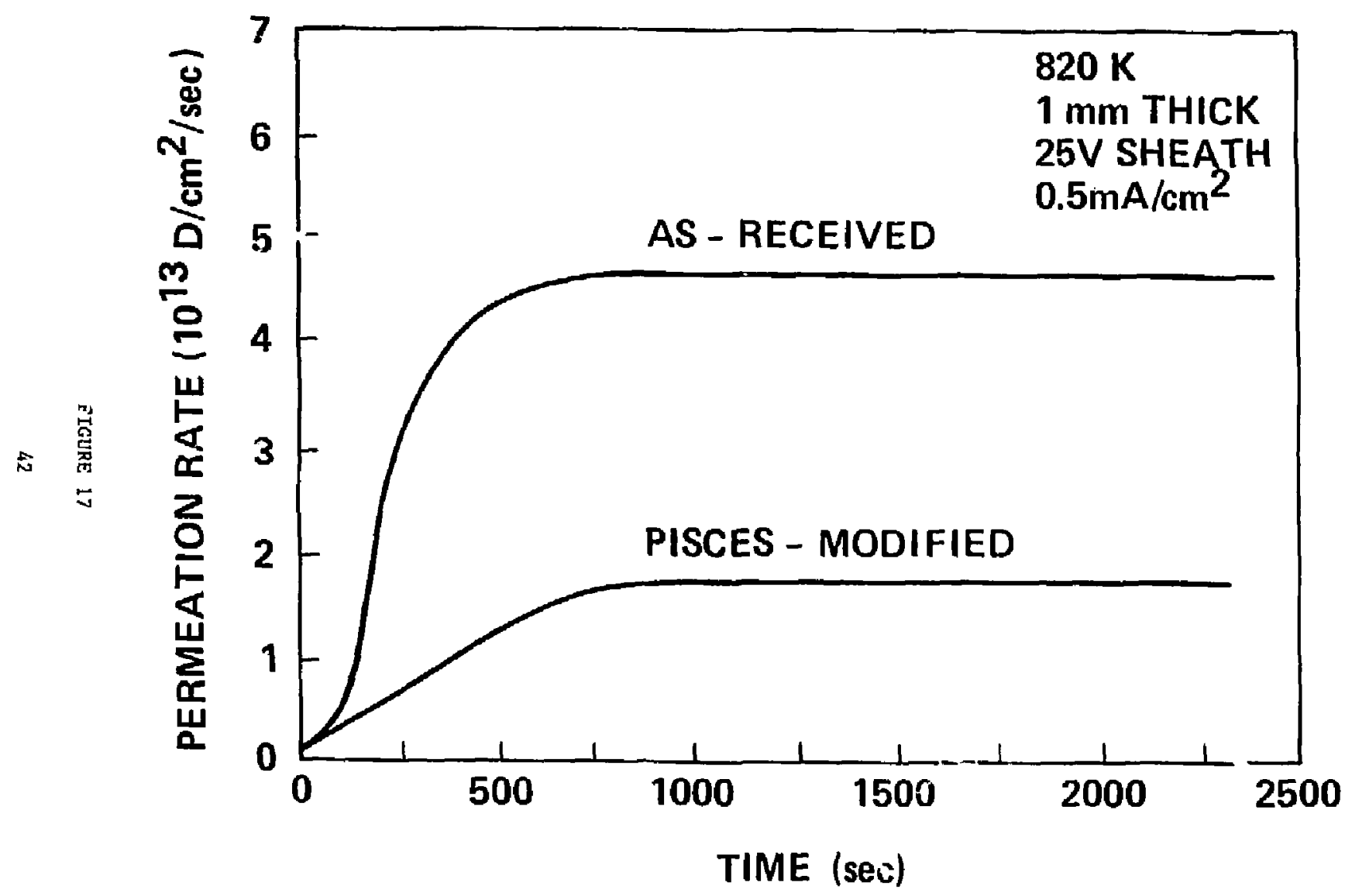

